Influencia del atractivo de la presentación de los vinos en la percepción de calidad e intención de consumo

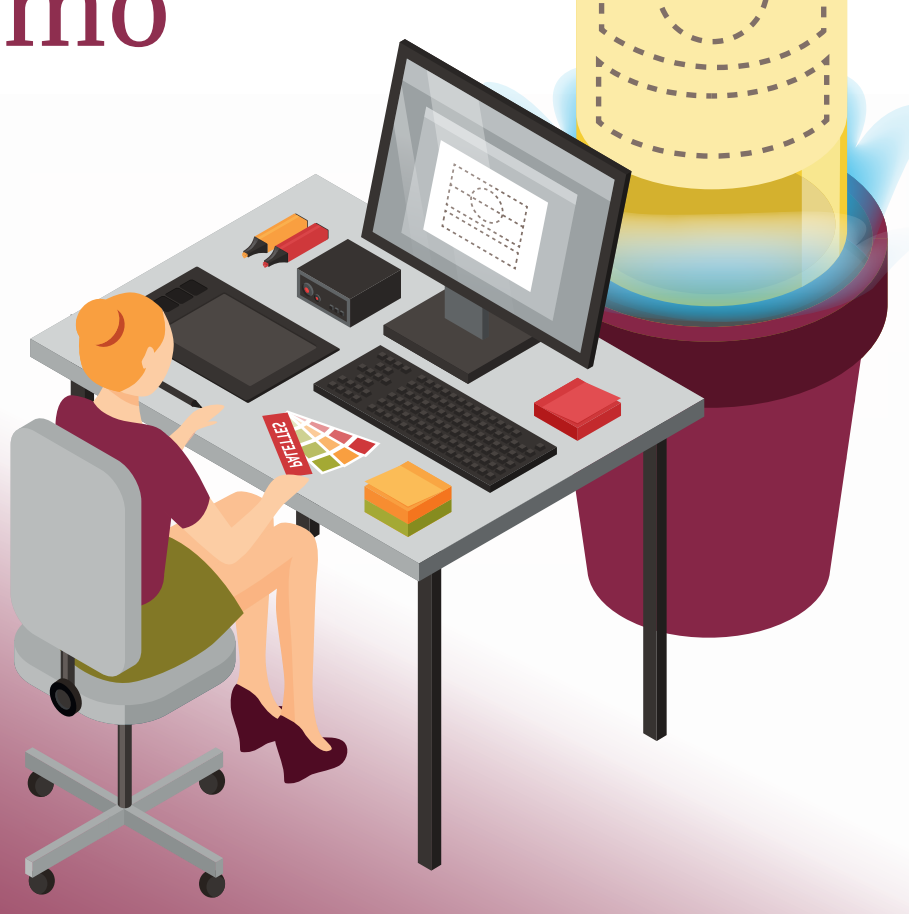


Edita:

Fundación General de la Universidad de La Laguna, Avenida de la Trinidad, 61, 38204.

San Cristóbal de La Laguna, S/C de Tenerife.

ISBN: 978-84-09-26702-6

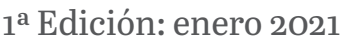

Proyecto financiado por el Instituto Canario de Calidad Agroalimentaria del Gobierno de Canarias.

Cómo citar esta publicación:

Díaz-Armas, R.J.; Gutiérrez-Taño, D.; Fernández-Martín, A.; Hernández-Méndez, J.; Ramos-Henríquez, J.M.; SabinaCastillo, E. \& Baute-Díaz, N. (2021). Influencia del atractivo de la presentación de los vinos en la percepción de calidad e intención de consumo. Tenerife: Fundación General de la Universidad de La Laguna.

DOI: https://doi.org/10.25145/b.Influenciavinos.2021 


\section{Equipo investigador}

Ricardo J. Díaz Armas

Desiderio Gutiérrez Taño

Andrés Fernández Martín

Janet Hernández Méndez

José Manuel Ramos Henríquez

Edgar Sabina del Castillo

Nisamar Baute Díaz 


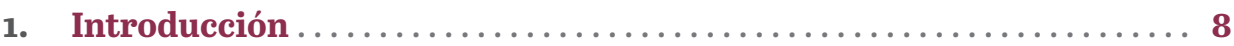

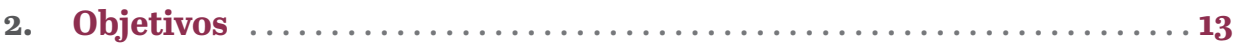

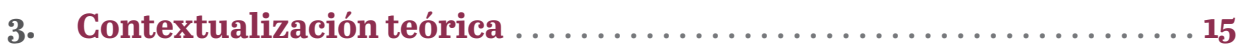

4. Metodología ..................................... 20

4.1. Encuesta a consumidores ...................................20

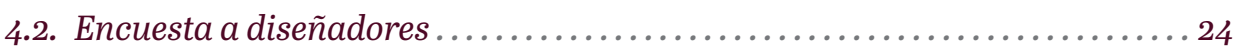

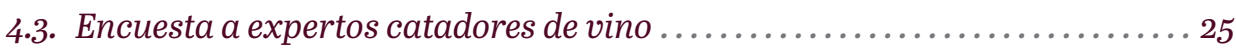

4.4. Selección de presentaciones ................................. 27

4.5. Análisis de datos ................................................. 28

5. Valoración global de las presentaciones de vino $\ldots \ldots \ldots \ldots \ldots \ldots$

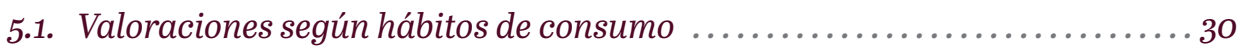

5.2. Valoraciones según características sociodemográficas ............... 32

6. Influencia del diseño de la presentación en el consumo y en la calidad percibida del producto $\ldots \ldots \ldots \ldots \ldots \ldots \ldots \ldots \ldots \ldots$

7. Variables moderadoras de las relaciones entre el atractivo de la presentación y las variables intención de consumo, percepción de calidad y pertenencia a categoría $\ldots \ldots \ldots \ldots \ldots . \ldots 38$

8. Categorización de presentaciones $\ldots \ldots \ldots \ldots \ldots \ldots \ldots \ldots \ldots \ldots$

8.1. Tipologías de diseño .................................... 47

8.2. Valoraciones de las tipologías por los consumidores .................50

9. Percepción de los expertos en vino $\ldots \ldots \ldots \ldots \ldots \ldots \ldots \ldots \ldots \ldots \ldots \ldots \ldots \ldots \ldots$

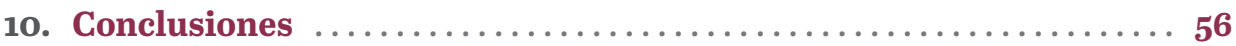

11. Recomendaciones ..............................64

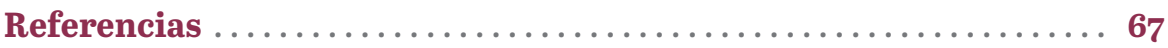


Índice de Tablas

Tabla 1. Características de la muestra de consumidores ................ 21

Tabla 2. Características de la muestra de diseñadores $\ldots . \ldots \ldots \ldots \ldots \ldots . \ldots 24$,

Tabla 3. Características de la muestra de expertos de vino ............... 26

Tabla 4. Moderación de la experiencia previa con la marca

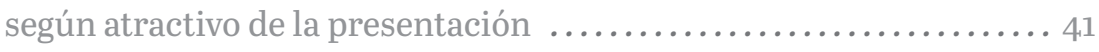

Tabla 5. Moderación de la edad según atractivo de la presentación........ 422

Tabla 6. Moderación del estatus socioeconómico

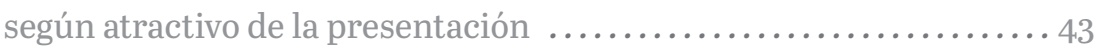

Índice de Gráficas

Gráfico 1. Valoración global de la selección de presentaciones de vinos según hábitos de consumo .............................. 30

Gráfico 2. Valoración global de la selección de presentaciones de vinos según características sociodemográficas .................... 32

Gráfico 3. Intención de consumo, diseño adecuado a la categoría y calidad percibida en función de lo atractivo de la presentación........... 36

Gráfico 4. Influencia del atractivo de la presentación en la intención de consumo ............................. 38

Gráfico 5. Influencia del atractivo de la presentación en la percepción de calidad ................................. 39

Gráfico 6. Influencia del atractivo en la valoración de la presentación como adecuada a la categoría ........................... 40

Gráfico 7. Tipologías de diseño según valoraciones de diseñadores $\ldots . \ldots . .48$ 


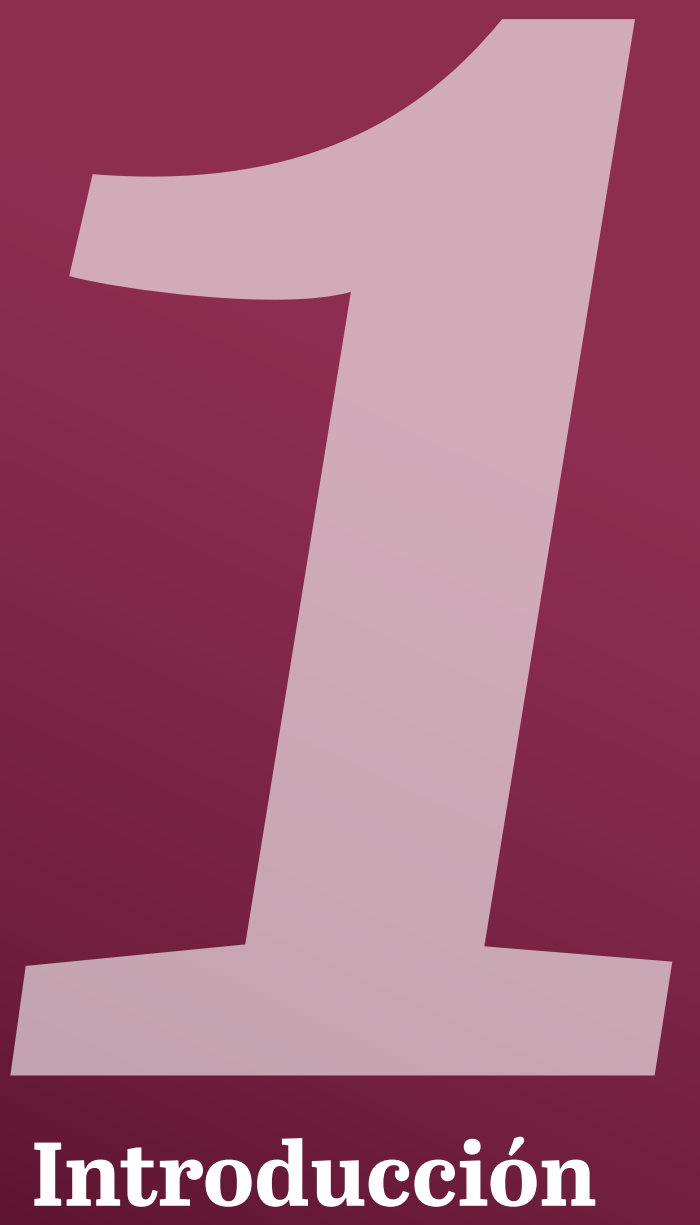

Influencia del atractivo de la presentación de los vinos en la percepción de calidad e intención de consumo 


\section{Introducción}

El presente documento recoge los resultados de un estudio que tiene como objetivo determinar el efecto del atractivo de la presentación o packaging del vino en la calidad percibida de este producto, así como en la probabilidad de consumirlo. Este estudio se ha centrado en el caso de los vinos producidos en Canarias.

El vino es uno de los productos agrícolas más importantes en Canarias. Se trata del cultivo que mayor superficie ocupa en las islas. De forma general, su producción contribuye al cuidado del territorio y a la conservación del paisaje. Si bien la producción de vino en las islas tiene un impacto relativamente bajo en el empleo y la economía, representa valores fundamentales ligados a la cultura tradicional canaria. Lo anterior hace que este producto sea un recurso atractivo también desde el punto de vista turístico, dado que su producción se suele relacionar con elementos vinculados a la autenticidad del territorio y la preservación de las costumbres y el desarrollo (agrícola) local. Desde este punto de vista sus efectos en la actividad turística son directos e indirectos.

No obstante, a pesar de la relevancia actual y potencial de este producto, la cuota de mercado del vino local respecto al consumo de vino en Canarias evidencia un importante margen de mejora. De hecho, durante muchos años la producción local no ha llegado a comercializarse en su totalidad.

La actividad económica vinculada al sector primario está pasando por momentos difíciles. De forma particular, el sector vitivinícola se encuentra afectado por la pérdida de tierras de cultivo y la cada vez mayor presencia de vinos foráneos, especialmente relevante en el canal de distribución alimentaria y canal Horeca (hostelería, restauración y cafetería). Este último, con una presencia relevante en los espacios turísticos, principal actividad económica de Canarias. A pesar de todo, las bodegas son cada vez más competitivas y la propuesta de valor de nuestros caldos ha ido mejorando y evolucionando, adquiriendo una posición sólida ante la competencia foránea.

No obstante, considerar un sector tan estratégico como el vinícola sólo desde un punto de vista económico es un gran error. Máxime en un marco social y económico determinado por la urbanización de los espacios, cambios en el estilo de vida de las personas y por ende cambios en las preferencias y hábitos alimentarios. El vinícola es un sector que muestra una minoración de su actividad en Canarias (ISTAC, 2020), por pérdida del relevo generacional, 
abandono de tierras, búsqueda de cultivos más competitivos, que afectarán al equilibrio social, económico y medioambiental de lo local. A este contexto habría que añadir la minoración, a nivel nacional, del consumo de vino en el canal alimentario en los últimos 20 años (OEMV, 2020).

En Canarias, el sector vinícola es y ha sido relevante en el aporte de riqueza local, con fuerte arraigo en la economía, la sociedad y el territorio. Esto se debe a que es un sector con capacidad de interrelación y arrastre de otras actividades, complementando su oferta. Actividades como son la restauración, la hostelería o transversalmente el turismo. Su importancia no es debida tanto a su contribución directa al producto interior bruto (PIB) de Canarias, como por el aporte y complemento a otras actividades que sí tienen un impacto relevante en el PIB. Actividades de servicios, en su mayoría de carácter experiencial, que sin el valor añadido de productos locales como el vino o las actividades en torno al vino carecerían de elementos de valor diferenciales.

El viñedo en Canarias ocupa, según diferentes estimaciones, en torno al 10\% del suelo agrícola del archipiélago (ICCA, 2010) o al 19-20\% según la agrupación de cultivos estimada por el Informe Estadístico del Mapa de Cultivos (Gobierno de Canarias, 2016), aunque con una gran pérdida acumulada en los últimos años (Elias-Pastor \& Contreras-Villaseñor, 2013). En Canarias, se ha perdido el $28 \%$ de superficie cultivada de viñedo entre el 2009 y 2019 , siendo Lanzarote la isla donde menos superficie se ha perdido con sólo un 4\%, y Fuerteventura y El Hierro donde mayor superficie se ha perdido con un $57 \%$ y un $52 \%$ respectivamente (ISTAC, 2020). Aunque no es homogénea la pérdida de zonas de cultivo en toda Canarias, tal y como ya determinaba Elias-Pastor \& Contreras (2013), esta tendencia es preocupante por las implicaciones

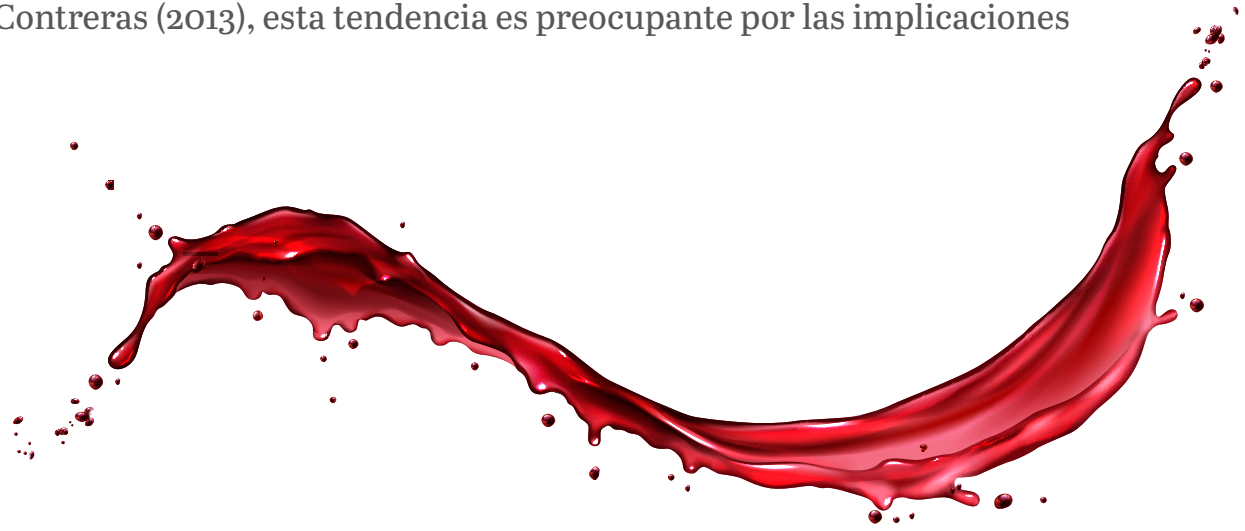


sociales y medioambientales que tiene. Por ello, es necesario fortalecer la comercialización de nuestros caldos y lograr un posicionamiento competitivo estable y duradero, frente a la oferta foránea.

Las circunstancias descritas previamente que afronta la producción y comercialización del vino canario, junto a la caída de las ventas desde que comenzó el estado de alarma por la Covid-19 (OEMV, 2020), hacen necesario seguir avanzando en la mejora de la propuesta de valor comercial de nuestros vinos locales. Para ello, el sector requiere innovar y un mayor conocimiento del comportamiento de compra y consumo del mercado actual. En este sentido, uno de los ejes en los que es necesario trabajar, para seguir consolidando dicha posición y ser capaz de transmitir los valores de diversidad, riqueza social y potencial del caldo con origen en Canarias, es el "packaging" del vino, la presentación del vino ante el consumidor.

Creemos que es estratégicamente relevante estudiar la comunicación emitida por la presentación del producto y sus implicaciones en el comportamiento del consumidor canario. El packaging debe transmitir algo más que los datos de obligado cumplimiento por la normativa vigente. Es el emisor del posicionamiento, debe comunicar los valores del producto y conectar con los deseos o intereses del consumidor. Botella y etiqueta son la imagen inicial a la que se enfrenta el potencial consumidor de vinos, con el ánimo de encontrar señales extrínsecas que le transmitan cuál es el vino que busca (Lockshin \& Corsi, 2020) y comprobar hasta qué punto se adapta la propuesta de valor percibida a la que desea adquirir.

Los resultados de este estudio pueden ayudarnos a conocer las implicaciones que tiene el diseño del packaging en la elección de un vino. Además, pueden ayudarnos a reflexionar sobre la estrategia de comunicación que hemos seguido y valorar la posibilidad de optimizar la imagen del producto para mejorar su percepción y su probabilidad de consumo. Con ello, los elementos de valor diferenciales que posee un vino canario y las exigencias de los diferentes segmentos de mercado del vino canario podrán estar en consonancia, siendo mayor la probabilidad de percepción de calidad del vino e intención de consumo, entre los vinos ofertados.

Esta línea de acción comercial que favorece la elección de un vino es determinante para mejorar la competitividad y conseguir la estabilidad que necesita el sector vitivinícola en Canarias, facilitando así el mantenimiento de la interrelación social, cultural y medioambiental de este sector de actividad. 
Para lograr estos objetivos se plantea en esta primera fase del proyecto la ejecución de una encuesta dirigida a tres colectivos, consumidores, diseñadores y expertos. En esta encuesta, a través de un cuestionario, se valorará el atractivo, la intención de compra, la calidad percibida y el ajuste del diseño a la categoría, de un grupo de botellas de vino de las diferentes islas, que recogen la diversidad de empaques que encontramos en los puntos de venta. 


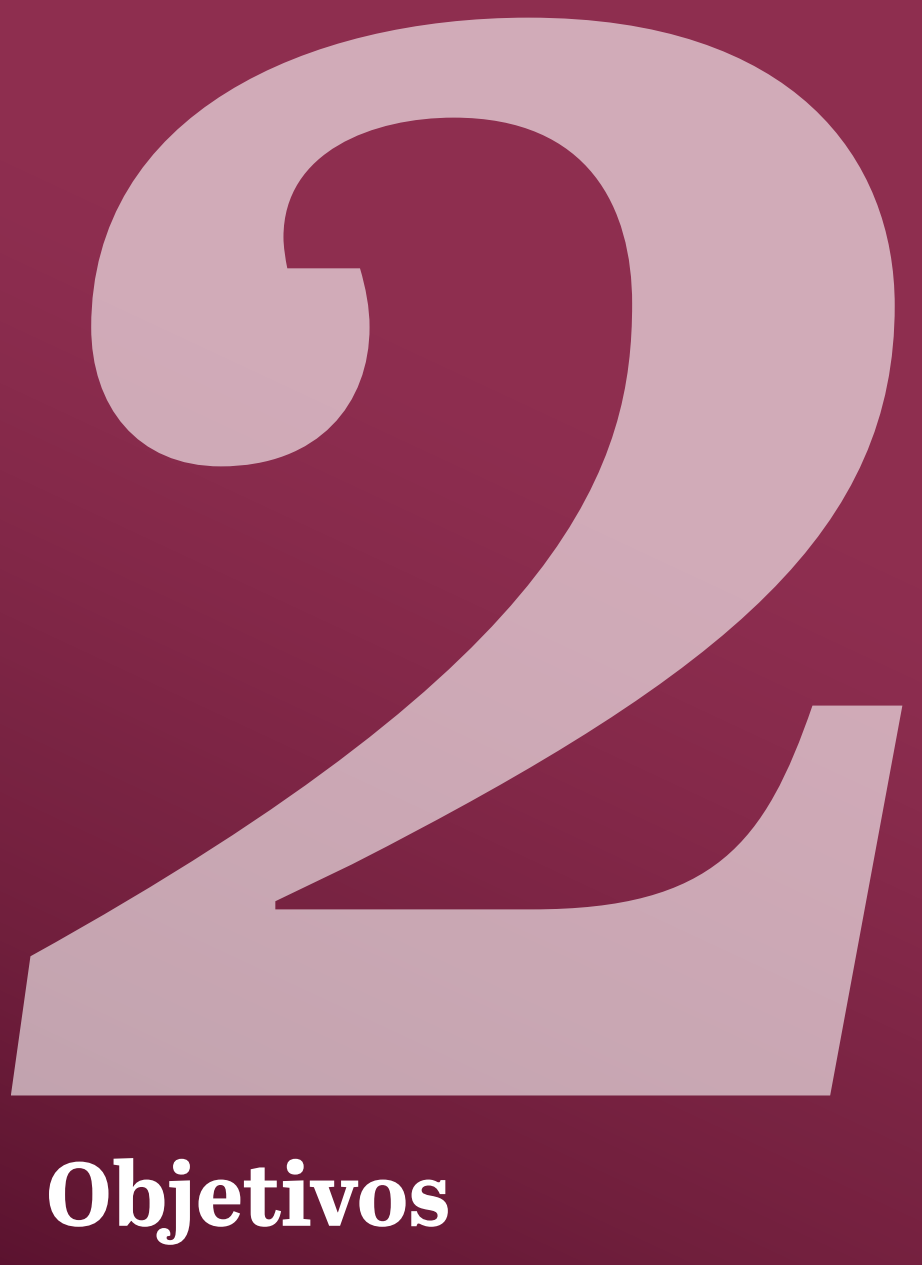

Influencia del atractivo de la presentación de los vinos en la percepción de calidad e intención de consumo 


\section{Objetivos}

En línea con los estudios que han identificado una clara influencia del diseño de la presentación (el packaging) en las decisiones de compra y en la percepción de calidad del producto, este estudio pretende conocer si (y en su caso, cómo) la imagen del producto afecta también al consumidor en el sector vinícola. El ámbito de estudio se centra en los vinos canarios.

De forma concreta, los objetivos específicos del estudio son:

Analizar la valoración del atractivo de las presentaciones de los vinos.

Conocer el efecto del diseño de la presentación de los vinos en la intención de consumo, la percepción de calidad y la adecuación a la categoría del producto.

Valorar el efecto de la frecuencia de consumo y la experiencia previa con la marca en la valoración de las presentaciones.

Valorar el efecto de variables sociodemográficas en la percepción del atractivo de las presentaciones (género, edad y nivel socioeconómico).

Categorizar las presentaciones en tipologías de diseño de acuerdo a criterios de los profesionales del diseño.

Conocer la valoración que hacen los consumidores del atractivo de las presentaciones en función de las tipologías de diseño identificadas.

Comparar la valoración objetiva sobre la calidad de los vinos realizada por expertos, con la percibida por los consumidores en función del diseño.

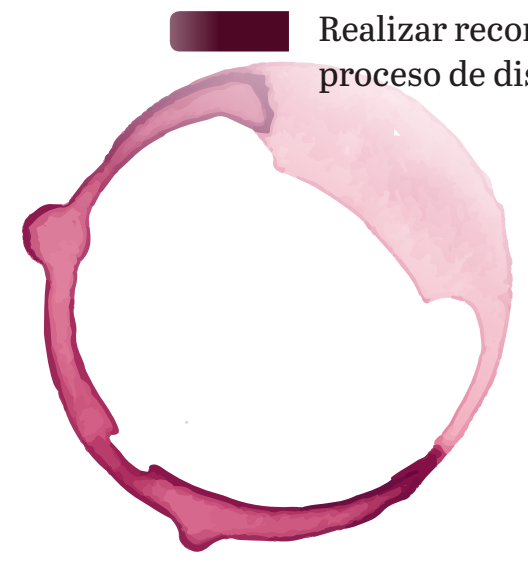

Influencia del atractivo de la presentación de los vinos en la percepción 


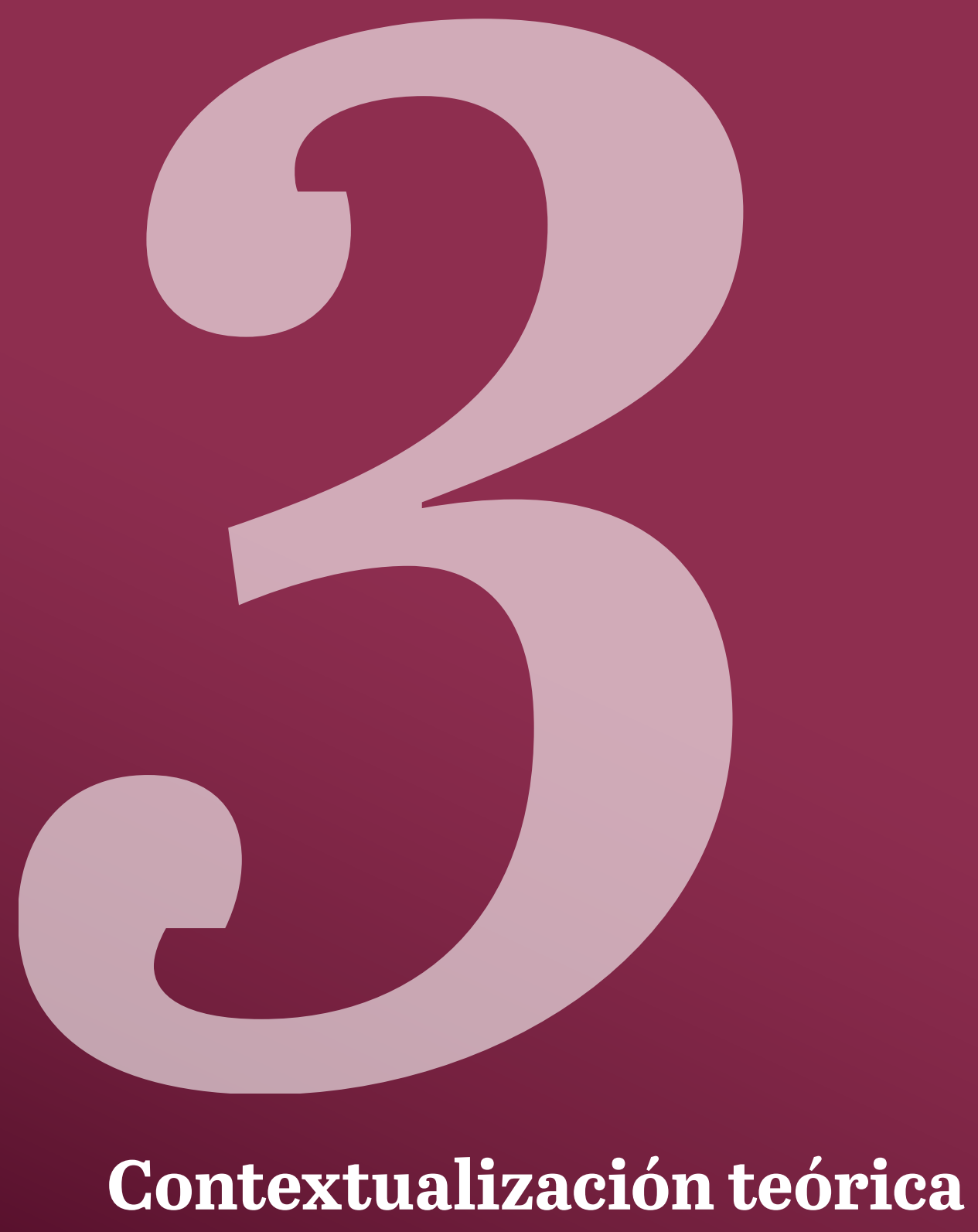




\section{Contextualización teórica}

La literatura científica centrada en el mundo del vino ha sido prolífica e incluso existen revistas especializadas y de calidad contrastada que se centran sólo en este producto y lo que le rodea. Tradicionalmente, y de forma comprensible, la investigación en el mundo del vino se ha focalizado en la enología, la viticultura y el análisis sensorial del vino (e.g., Goode, 2005, 2016; Zoecklein, Fugelsang, Gump y Nery, 1995). No obstante, en las últimas décadas ha aumentado exponencialmente el interés por lo que se denomina como "psicología del vino" (Spence, 2020). Esto ha permitido que se tenga conciencia de cómo una amplia variedad de factores cognitivos y perceptivos (Rozin, 2006) sesgan la percepción del vino y la experiencia de cata, tanto en los consumidores habituales como en los expertos. La botella, la copa, la apariencia del vino, la etiqueta, el contexto, el precio o la marca son algunos de estos factores.

Locksin y Corsi (2020) dejan claro en su aportación, y en los trabajos publicados por los autores en el pasado (Lockshin y Corsi, 2012; Lockshin y Cohen, 2011; Lockshin y Hall, 2003), que el vino no es simplemente un producto físico que reúne características organolépticas. Es un paquete de valor lleno de significado, experiencias, valores y deseos que los consumidores asocian al contenido de la botella y cómo ha llegado dicho contenido hasta ella (DíazArmas et al., 2020). El vino ofertado debe comunicar a su público objetivo a través de señales extrínsecas que el vino es adecuado a sus expectativas, señales extrínsecas que permitirán realizar una evaluación de los atributos intrínsecos del vino y por tanto de la calidad del vino (Di Vita, Caracciolo, Brun y D'Amico, 2019). Zeithaml (1988) consideraba el packaging como un conjunto de atributos, intrínsecos y extrínsecos, de tal forma que no podría cambiar ningún atributo sin alterar la naturaleza del producto, de su representación.

La investigación relativa a cualquiera de estas variables o atributos, y sus efectos en la percepción o consumo del vino es mayor que en cualquier otro producto de alimentación. Así, por ejemplo, se ha estudiado mucho el impacto de la etiqueta en el comportamiento de consumo (véase Boudreaux y Palmer, 2007; Charters, Lockshin y Unwin, 1999; Cutler, 2006; Gmuer, Siegrist y Dohle, 2015; Mueller, Lockshin, Saltman y Blanford, 2010; Shaw, Keeghan y Hall, 1999; Thomas y Pickering, 2003), y se ha confirmado que aspectos teóricamente "irrelevantes" como el color o el diseño de las etiquetas influyen en las expectativas que los consumidores se hacen sobre el vino (e.g., Heatherly, Dein, Munafo y Luckett, 2019; Lick y col., 2017; Lunardo y Livat, 2016). 
El packaging (incluyendo la etiqueta y contraetiqueta) no es un mero elemento que contiene y protege el producto. Se trata de un vehículo de comunicación gracias a la información que se ofrece del producto y a aspectos como el color, la forma, el diseño o el mensaje (Silayoi y Speece, 2004, 2007) que pueden atraer la atención del consumidor (Gelici-Zeko et al., 2013), definir aspectos tan relevantes como la calidad del producto (Venter et al., 2011), o influir en las decisiones de compra (Abdullah y Anagreh, 2011).

No sólo se ha identificado el poderoso efecto del diseño del envase de un producto en las decisiones de compra de los consumidores (e.g., Newman, 2009), otros estudios también han mostrado que aspectos como el diseño, el color y el material -los elementos visuales y físicos- de los packaging, son más influyentes con respecto a las intenciones de compra de los consumidores que los elementos meramente informativos (Karimi, Mahdieh y Rahmani, 2013).

El productor de vino ha de ser consciente en la fase de diseño del packaging del paquete del valor que desea comunicar. Para ello requiere considerar qué señales lograrán persuadir a su público objetivo tratará de encontrar durante la decisión de compra. Con el fin de seducir al consumidor, el packaging emite una imagen que se percibe de manera conjunta (Thomas, 2000). Esta imagen

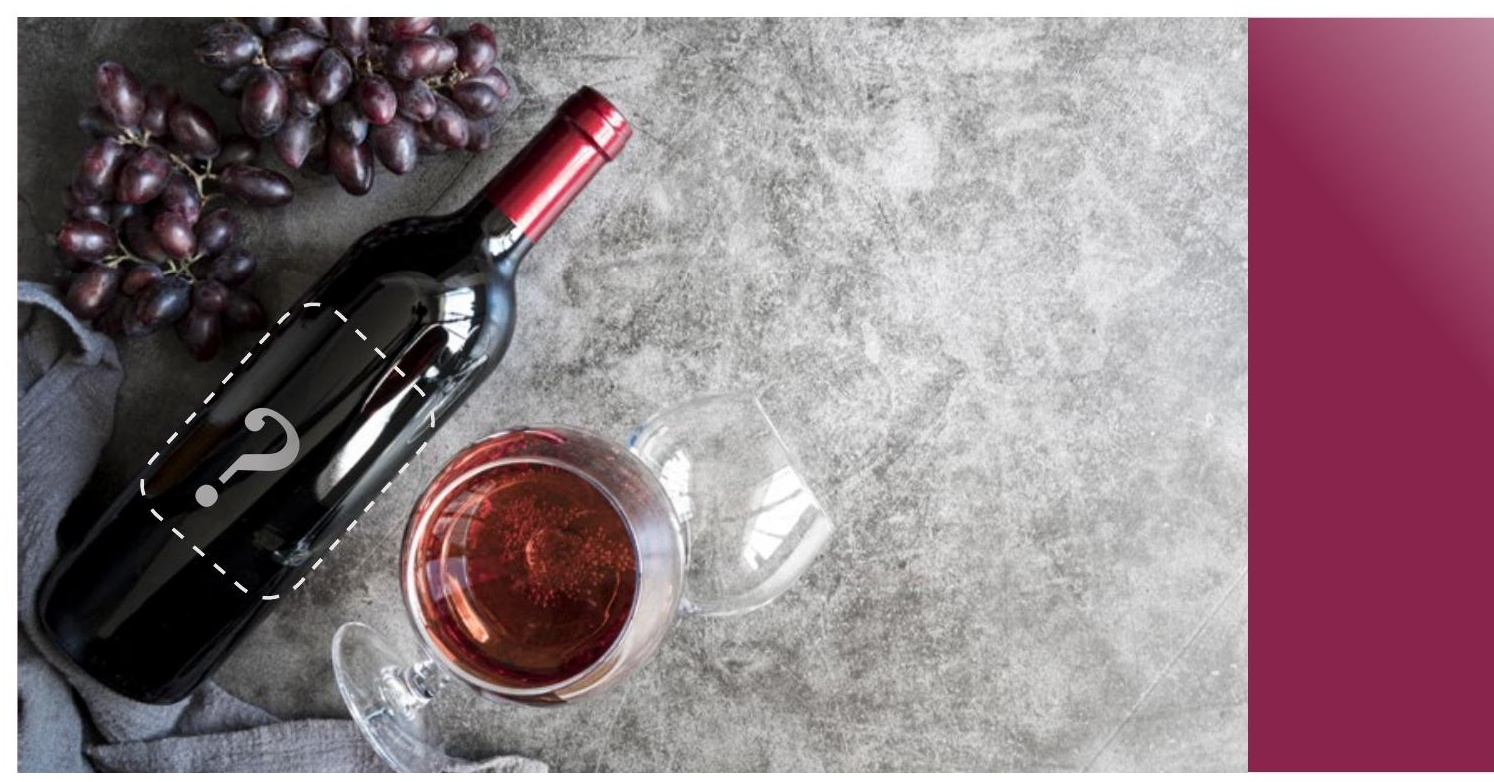

Influencia del atractivo de la presentación de los vinos en la percepción de calidad e intención de consumo 
conjunta se diseña para que un vino tenga éxito en el mercado, si bien antes debe existir consonancia entre los atributos del vino, intrínsecos, y las señales emitidas por el packaging, extrínsecas (Mueller \& Szolnoki, 2010). No puede existir contradicción entre lo emitido conjuntamente y la experiencia durante el consumo del vino.

Además, la percepción de la imagen conjunta que transmite la presentación de un vino estará condicionada según el consumidor que la observe (Lockshin y Hall, 2003) y varía según el público objetivo al que se dirija, ya que éste busca o percibe señales extrínsecas diferentes según pertenezcan a generaciones más jóvenes (Atkin y Thach, 2012). Otro elemento que afecta esta percepción es el mayor o menor nivel de experiencia o implicación en el mundo del vino (Rahman y Reynolds, 2015). En productos como el vino, el consumidor que no está familiarizado con el producto en general, la marca o la bodega, percibe riesgo en la elección. El consumidor no tiene la capacidad de evaluar los atributos intrínsecos (Zeithaml, 1988) y, por tanto, las señales emitidas extrínsecamente son determinantes.

¿Cómo es esto posible? Las primeras impresiones y las apariencias físicas tienen relevancia en la elección del producto por parte de los consumidores (Adofo, 2014). Cuando los consumidores observan el diseño del packaging de un producto, no solo se forman una impresión sobre el diseño del packaging sino también sobre el producto (Grundey, 2010) confiando en el hecho de que él mismo proyecta las características del producto. En consecuencia, si el diseño del envase parece "de calidad", los consumidores generalmente predicen que el producto es de alta calidad y viceversa (Abdelazim-Mohamed, GarcíaMedina y González-Romo, 2019). En muchos casos, los juicios de valor de los consumidores sobre los productos se basan en el atractivo del envase, por lo que se forma un vínculo entre el atractivo y las decisiones de compra (Lo et al, 2013).

Un empaque menos atractivo sólo tiene sentido cuando el comprador no busca elementos de valor hedónicos y principalmente busca beneficios como minoración en precio (Orth, Campana, y Malkewitz, 2010). En caso contrario, el diseño de empaques poco atractivos afectará a la percepción de calidad del producto y reducirá la intención o probabilidad de compra (Orth y Malkewitz, 2008). 
En esta línea, estudios conductuales, de potenciales evocados y de resonancia magnética han estudiado la respuesta al atractivo. No sólo se han encontrado que áreas cerebrales relacionadas con la atención visual, la memoria y la recompensa se activan ante un packaging atractivo (mientras que ante uno no atractivo se activan áreas relacionadas con el riesgo, el asco, el conflicto o la incertidumbre; véase Stoll, Baecke y Kenning, 2008), sino que se ha evidenciado que el procesamiento del atractivo de un estímulo tiene lugar rápidamente (entre los 400 y los 600 milisegundos tras la visualización del estímulo) y sesga las valoraciones posteriores que se hagan del mismo (e.g., Gutiérrez-García, Calvo y Beltrán, 2018). Esta sería una constatación más de que el cerebro humano emplea atajos mentales basados en el axioma "lo bello es bueno" a la hora de valorar o formarnos expectativas de los productos o las personas.

Si el cerebro humano es sensible al atractivo de un packaging y utiliza esta información superficial para formarnos una expectativa del producto que contiene, ¿en qué medida un packaging atractivo puede sesgar la percepción del producto a la hora de valorar su calidad o influir en su preferencia de consumo? ¿Es aplicable a un producto como el vino? Este fue el objetivo fundamental de este estudio. 


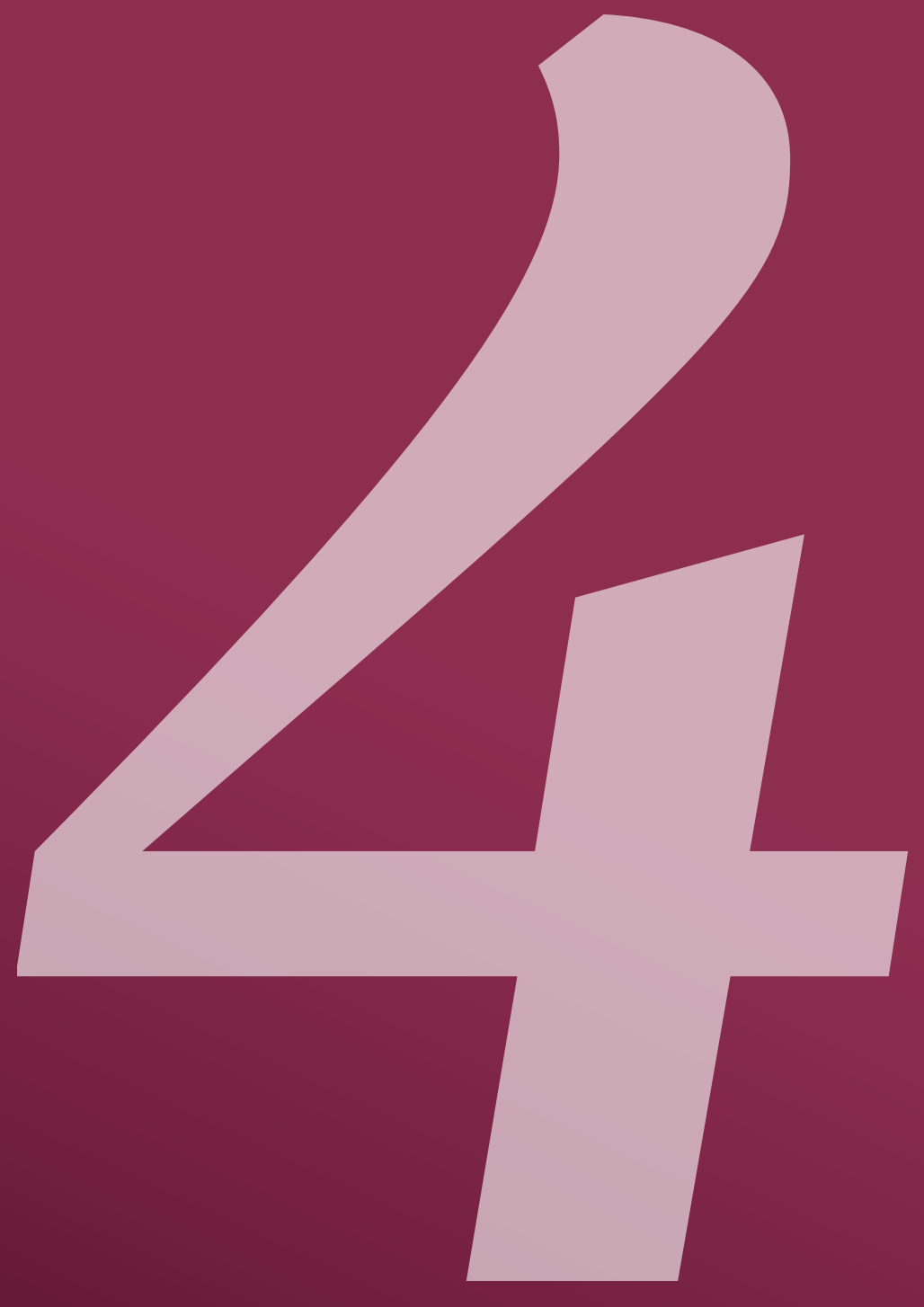

Hábitos de consumo de vino 


\section{Metodología}

Para la consecución de los objetivos propuestos se ha seguido una metodología que triangula tres encuestas online autoadministradas: una a consumidores de vino, otra a diseñadores y otra a expertos catadores de vino.

En la encuesta a consumidores, cada participante visualizaba imágenes en las que se presentaban (de una en una) una serie de botellas de vino. Su tarea consistía en valorar el atractivo de la presentación del producto (packaging), la percepción de calidad del producto, la probabilidad de consumirlo y el grado en que la presentación del producto se adecuaba a la categoría del mismo. De esta forma, se puede determinar la influencia del diseño en la probabilidad de consumo y en la percepción de calidad.

Por su parte, con la encuesta a diseñadores se pretendía identificar tipologías de presentaciones de vino en función de criterios de diseño (transgresión, emotividad, trabajado, elegancia, coherencia con categoría), al objeto de conocer, con las respuestas de los consumidores, aquellas tipologías que son percibidas como más atractivas y las potencialidades y riesgos de los estilos de diseño.

Finalmente, con la encuesta a expertos se pretendía conocer la percepción de calidad intrínseca/objetiva de los vinos y relacionarla con la calidad percibida por parte de los consumidores (no expertos) en función del atractivo del diseño.

Los trabajos de recogida de información se realizaron en el mes de diciembre de 2020.

\subsection{Encuesta a consumidores}

La encuesta a consumidores se realizó a través de un panel. Los participantes en el estudio fueron personas mayores de 18 años, consumidores de vino (al menos una vez cada 15 días) residentes en Canarias. La empresa de paneles de internet Toluna (http://www.toluna-group.com), fue la encargada de obtener la muestra con las características establecidas. Los paneles de Internet se utilizan cada vez más como un medio viable para la obtención de datos debido a la amplia disponibilidad de Internet entre diversos grupos y los medios de recogida de datos eficientes y de bajo costo que ofrece Internet (Roster et al., 2004). Además, Liu et al (2010) han demostrado que la representatividad de los 
datos de Internet es comparable a los datos de muestras probabilísticas de la población general.

Para reclutar a los individuos del estudio, Toluna envió correos electrónicos para invitar a los potenciales participantes de sus bases de datos para inscribirse en el estudio después de un proceso de selección para asegurar la elegibilidad. Se obtuvo una muestra de 347 personas que cumplimentaron el cuestionario y cumplían los requisitos exigidos. Los participantes que completaron la totalidad del cuestionario fueron compensados según los incentivos establecidos por Toluna, que establece un control de calidad a través de los procedimientos que tiene implementados.

Para un nivel de confianza del $95,5 \%$ y p $=\mathrm{q}$, el error muestral es de $\pm 5,4 \%$ para el conjunto de la muestra y en el supuesto de muestreo aleatorio simple. En la tabla 1 se recoge el perfil de los encuestados. $\mathrm{Al}$ analizar la muestra resultante, por género, el 49,0\% es femenino y el 51,0\% masculino. Atendiendo a la edad, el $17,6 \%$ tienen entre 18 y 30 años, el $35,4 \%$ entre 31 y 45 años y el $47 \% 46$ años o más. Según el nivel de estudios, un $62,2 \%$ tiene estudios universitarios y un $37,7 \%$ primarios/secundarios. La influencia del nivel socioeconómico se ha analizado de forma indirecta según la valoración que hacía el participante sobre "cómo considera el nivel de ingresos familiar". En la muestra resultante un 18,4\% consideró sus ingresos por debajo de la media, un 55,0\% en la media y un $24,8 \%$ por encima de la media. Según la isla de residencia, un $60,2 \%$ de la muestra resultante representa a consumidores de Tenerife, un 4\% de La Palma, un 0,6\% de La Gomera, un 0,3\% de El Hierro, un 25,4\% de Gran Canaria, un 3,7\% de Lanzarote y un $5,5 \%$ de Fuerteventura.

Tabla 1. Características de la muestra de consumidores

Género

\begin{tabular}{ll}
\hline Femenino & $49,0 \%$ \\
\hline Masculino & $51,0 \%$ \\
\hline Edad & \\
\hline $18-30$ & $17,6 \%$ \\
\hline $31-45$ & $35,4 \%$ \\
\hline$>=46$ & $47,0 \%$ \\
\hline
\end{tabular}




\begin{tabular}{|c|c|}
\hline \multicolumn{2}{|l|}{ Nivel de estudios } \\
\hline Básicos / Primaria & $1,7 \%$ \\
\hline Secundaria/Bachillerato/FP & $36,0 \%$ \\
\hline Universitarios & $62,2 \%$ \\
\hline \multicolumn{2}{|l|}{ Actividad que desempeña } \\
\hline Autónomo/a & $13,8 \%$ \\
\hline Empresario/a & $5,2 \%$ \\
\hline Directivo/a & $5,2 \%$ \\
\hline Mando intermedio & $14,1 \%$ \\
\hline Asalariado/a & $36,3 \%$ \\
\hline Jubilado/a & $8,9 \%$ \\
\hline Estudiante & $3,5 \%$ \\
\hline Actividades del hogar & $1,7 \%$ \\
\hline Desempleado/a & $11,2 \%$ \\
\hline \multicolumn{2}{|l|}{ Isla de residencia } \\
\hline Tenerife & $60,2 \%$ \\
\hline La Palma & $4,0 \%$ \\
\hline La Gomera & $0,6 \%$ \\
\hline El Hierro & $0,3 \%$ \\
\hline Gran Canaria & $25,6 \%$ \\
\hline Lanzarote & $3,7 \%$ \\
\hline Fuerteventura & $5,5 \%$ \\
\hline \multicolumn{2}{|l|}{ Ingresos } \\
\hline Por debajo de la media & $18,4 \%$ \\
\hline En la media & $55,0 \%$ \\
\hline Por encima de la media & $24,8 \%$ \\
\hline No sabe & $1,7 \%$ \\
\hline Total & 347 \\
\hline
\end{tabular}

De las respuestas de las 347 personas que han contestado al cuestionario se han obtenido 7.513 valoraciones de las presentaciones estudiadas. 
El cuestionario utilizado se ha estructurado en los siguientes apartados:

1) Filtro:

- Frecuencia de consumo de varios productos para determinar si es consumidor de vino.

- Edad para restringir el acceso al cuestionario sólo a los mayores de 18 años.

2) Aspectos tenidos en cuenta a la hora de elegir vino (pregunta abierta).

3) Presentación de 28 botellas de vino. En cada una de ellas se debían valorar los siguientes aspectos en una escala de 1 a 10:

- Atractivo de la presentación del vino.

- Diseño apropiado para un vino.

- $\quad$ Probabilidad de consumo.

- Percepción de la calidad del vino.

- Conocimiento previo.

4) Hábitos de consumo:

- $\quad$ Tipo de vino.

- Criterios de elección.

5) Datos de clasificación:

- Género.

- Nivel de estudios.

- Actividad.

- Isla/municipio de residencia.

- Ingresos familiares. 


\subsection{Encuesta a diseñadores}

Han participado 18 profesionales del diseño o de la comunicación para valorar las presentaciones/diseños de los vinos estudiados. Se han obtenido 504. valoraciones de las botellas presentadas.

En la tabla 2 se presenta el perfil de los profesionales del diseño que han valorado las imágenes de los productos estudiados. Doce son diseñadores, 2 creativos publicitarios, 1 publicista, 2 responsables de marketing y 1 director de arte.

Tabla 2. Características de la muestra de diseñadores

\begin{tabular}{lr} 
Diseñador & 12 \\
\hline Creativo de campañas publicitarias & 2 \\
\hline Publicista & 1 \\
\hline Responsable de marketing/comunicación & 2 \\
\hline Dirección de arte & 1 \\
\hline Total & 18
\end{tabular}

Para determinar los criterios de diseño se partió de los valores asociados al grado de elaboración o complejidad en el diseño gráfico (Favier, Celhay, \& Pantin-Sohier, 2019) y, tras contrastarlos con diseñadores por medio de entrevistas en profundidad, se identificaron una serie de ítemes que permitieron definir una escala para establecer tipologías de diseño.

El cuestionario utilizado para que los profesionales del diseño valoraran las presentaciones de vinos, se estructuró en los siguientes apartados: 
1) Presentación de 28 botellas de vino. En cada caso se pedía situarla en una escala de diferencial semántico de 7 puntos en los siguientes criterios definitorios del diseño:

- Transgresor vs. Convencional.

- Emocional vs. Frío.

- Moderno vs. Anticuado.

- Diseño cuidado vs. Diseño descuidado.

- Elegante, fino vs Vulgar, corriente.

- Coherente con categoría vino vs. Incoherente con categoría vino.

2) Actividad principal (Diseñador, creativo, publicista, ....)

\subsection{Encuesta a expertos catadores de vino}

Han participado 21 expertos de vino para valorar la calidad técnica de la muestra de vinos utilizadas en el estudios. Se han obtenido 224 valoraciones de los vinos presentados.

En la tabla 3 se presenta el perfil de los profesionales expertos en vino que han valorado la calidad técnica de los vinos de acuerdo a su conocimiento previo de los mismos. Por género 5 son mujeres y 16 hombres, según estudios 6 tienen educación secundaria, 9 universitaria y 6 formación profesional especializada en viticultura y/o enología; según actividad profesional, 3 son viticultores/ bodegueros, 4 enólogos, 8 sommelier, 2 restauradores y 4 , técnicos de la administración. 
Tabla 3. Características de la muestra de expertos de vino

\begin{tabular}{lr} 
Género & 5 \\
\hline Femenino & 16 \\
\hline Masculino & \\
\hline Nivel de estudios & 6 \\
\hline Secundaria/Bachillerato/FP & 9 \\
\hline Universitarios & 6 \\
\hline Formación Profesional especializada viticultura/enología & 3 \\
\hline Actividad profesional & 4 \\
\hline Viticultor/Bodeguero & 8 \\
\hline Enólogo & 2 \\
\hline Sommelier & 4 \\
\hline Restaurador & 21 \\
\hline Técnico administración & \\
\hline Total &
\end{tabular}

El cuestionario utilizado se ha estructurado en los siguientes apartados:

1) Percepción de lo que creen que tienen en cuenta los consumidores a la hora de elegir vino

2) Presentación de 28 botellas de vino. Para cada una de ellas se pedía una valoración respecto a los siguientes aspectos:

- Atractivo de la presentación del vino.

- Diseño apropiado para un vino.

- Probabilidad de ser consumido por los consumidores.

- Opinión sobre la calidad de este vino. 
3) Datos de clasificación:

- Género.

- Edad.

- $\quad$ Nivel de estudios.

- Actividad (Viticultor, bodeguero, enólogo, catador, sommelier, ...).

\subsection{Selección de presentaciones}

De entre más de 200 diseños de packaging de vinos canarios se llevó a cabo una selección de vinos intentando tener una representación variada de los mismos que permitiera analizar los objetivos del estudio. Para ello se tuvieron en cuenta los siguientes criterios:

- Diversidad de formas de botella.

- Diversidad de formatos y estilos de etiquetas.

- $\quad$ DOP de origen del vino.

- $\quad$ Tipo de vino (tinto, blanco, ...).

- Recorrido de las bodegas.

Del total de los diseños posibles, se han elegido 28 (y no más) porque después de llevar a cabo un pretest, el tiempo de contestación del cuestionario era aproximadamente de 15 minutos. Se trata de una duración algo por encima del tiempo máximo recomendado para una encuesta online autoadministrada. Estos 28 diseños fueron presentados a los consumidores, diseñadores y expertos para que los valoraran en los atributos correspondientes. 


\subsection{Análisis de datos}

El análisis de los datos se ha realizado a través de las tabulaciones de las variables dependientes a explicar frente a las independientes, utilizando software estadístico apropiado que permite el contraste de las diferencias de medias y de proporciones realizadas.

Para analizar el efecto de las distintas variables según lo atractivo de la presentación del vino, esta variable se ha categorizado en dos niveles: atractivo alto para valores iguales o mayores a $7 \mathrm{y}$ atractivo bajo para valores menores a 7 (escala de 1 a 10).

En el estudio también se analiza si algunas variables como conocimiento de la marca, frecuencia de consumo, género, edad y estatus socioeconómico pueden estar ejerciendo un efecto moderador en las relaciones entre el atractivo de la presentación y las variables intención de consumo, percepción de calidad y diseño apropiado para un vino. 


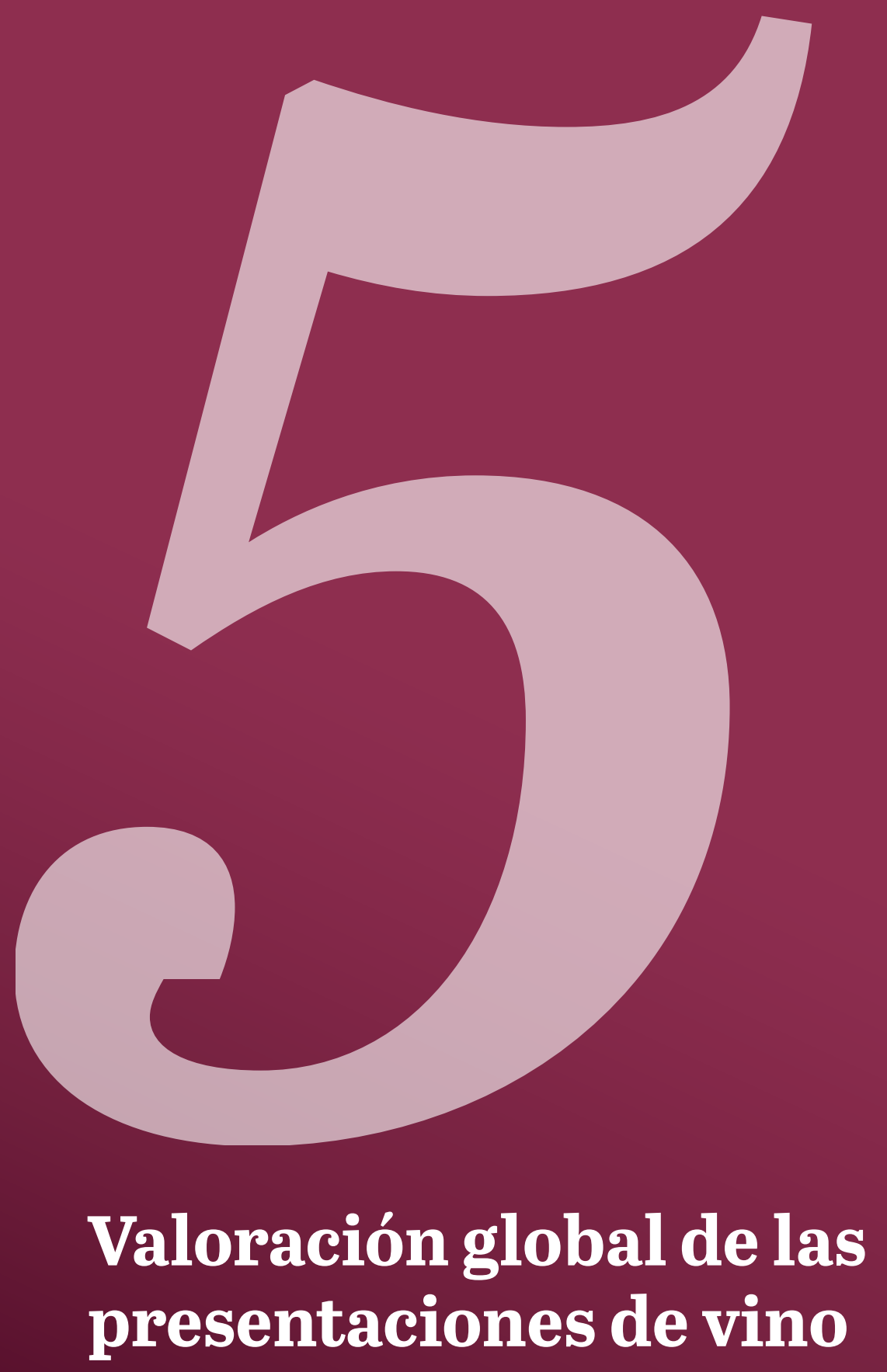




\section{Valoración global de las presentaciones de vino}

\subsection{Valoraciones según hábitos de consumo}

En el gráfico 1 se muestran las puntuaciones medias en atractivo del diseño, probabilidad de consumo y percepción de calidad de todas las presentaciones de vinos, en función de los hábitos de consumo y experiencia previa (nivel de conocimiento previo del vino, frecuencia de consumo de vino).

\section{Gráfico 1. Valoración global de la selección de presentaciones de vinos} según hábitos de consumo

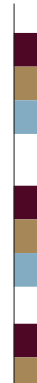

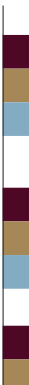

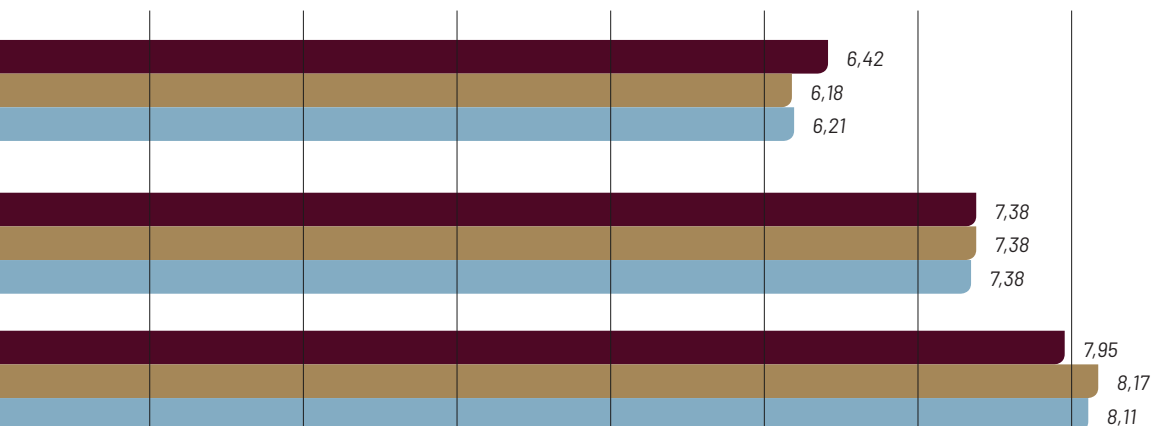

Una vez cada 15 días

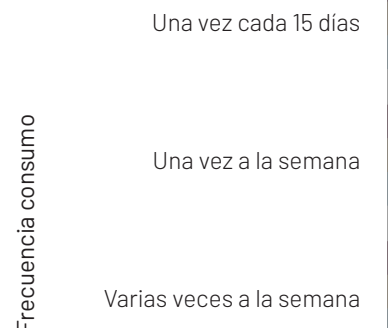

Varias veces a la semana

Diariamente

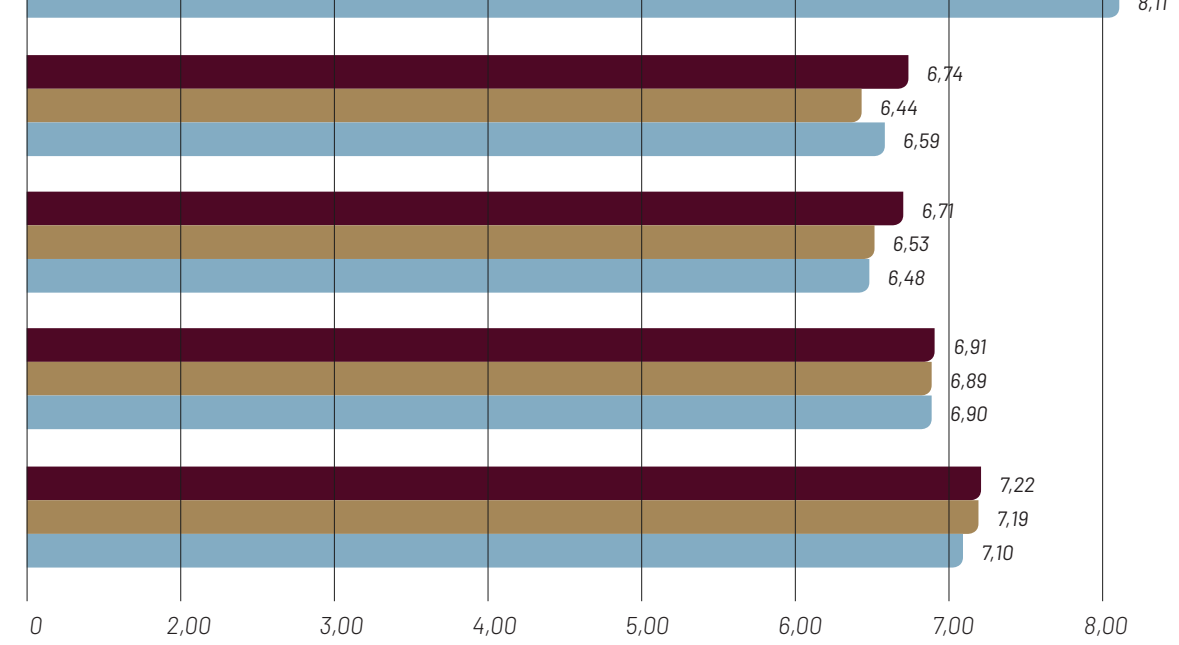




\section{Experiencia previa con la marca}

Puede observarse que a medida que la experiencia previa con el vino aumenta también lo hacen las variables analizadas. Así, en una escala de 1 (poco atractivo) a 10 (muy atractivo) la puntuación media al valorar el atractivo de la presentación es de 6,42 para los que no conocen el vino, de 7,38 para los que lo conocen pero no lo han probado y de 7,95 para los que lo han probado. Por su parte, la probabilidad media de consumo es de 6,18 para los que no conocen el vino, de 7,38 para los que lo conocen pero no lo han probado y de 8,17 para los que lo han probado. Igualmente, la puntuación media al valorar la percepción de calidad es de 6,21 para los que no conocen el vino, de 7,35 para los que lo conocen pero no lo han probado y de 8,11 para los que lo han probado.

\section{Frecuencia de consumo}

En relación con la frecuencia de consumo, los que consumen vino con mayor asiduidad muestran puntuaciones más altas al juzgar el atractivo de un vino, al valorar su calidad y al estimar la probabilidad de consumirlo. En cuanto al atractivo, la puntuación media es de 6,74 para los que consumen una vez a la semana o menos, de 6,91 para los que consumen vino varias veces a la semana, y de 7,22 para los que consumen diariamente. Lo mismo sucede respecto a la probabilidad de consumo. En este caso, la probabilidad media de consumo es de 6,53. Para los que consumen vino varias veces a la semana es de 6,89 y para los que consumen diariamente es de 7,19. Igualmente, al analizar la percepción de la calidad se observa esta misma tendencia. Así, la media de la percepción de calidad es de 6,48, mientras que para los que consumen vino varias veces a la semana es de 6,90 y para los que consumen diariamente es de 7,10.

Además, es destacable que la influencia de la experiencia con la marca es más fuerte que la frecuencia de consumo. Tener la marca en la mente, reconocerla y haberla consumido refuerza aún más la percepción de atractivo y la percepción de calidad del vino. Esto conlleva una mayor probabilidad de consumo. 


\subsection{Valoraciones según características sociodemográficas}

En el gráfico 2 se muestran las puntuaciones medias en atractivo del diseño, probabilidad de consumo y percepción de calidad de todas las presentaciones de vinos, según las características sociodemográficas de los consumidores (género, la edad y el estatus socioeconómico).

Gráfico 2. Valoración global de la selección de presentaciones de vinos según características sociodemográficas

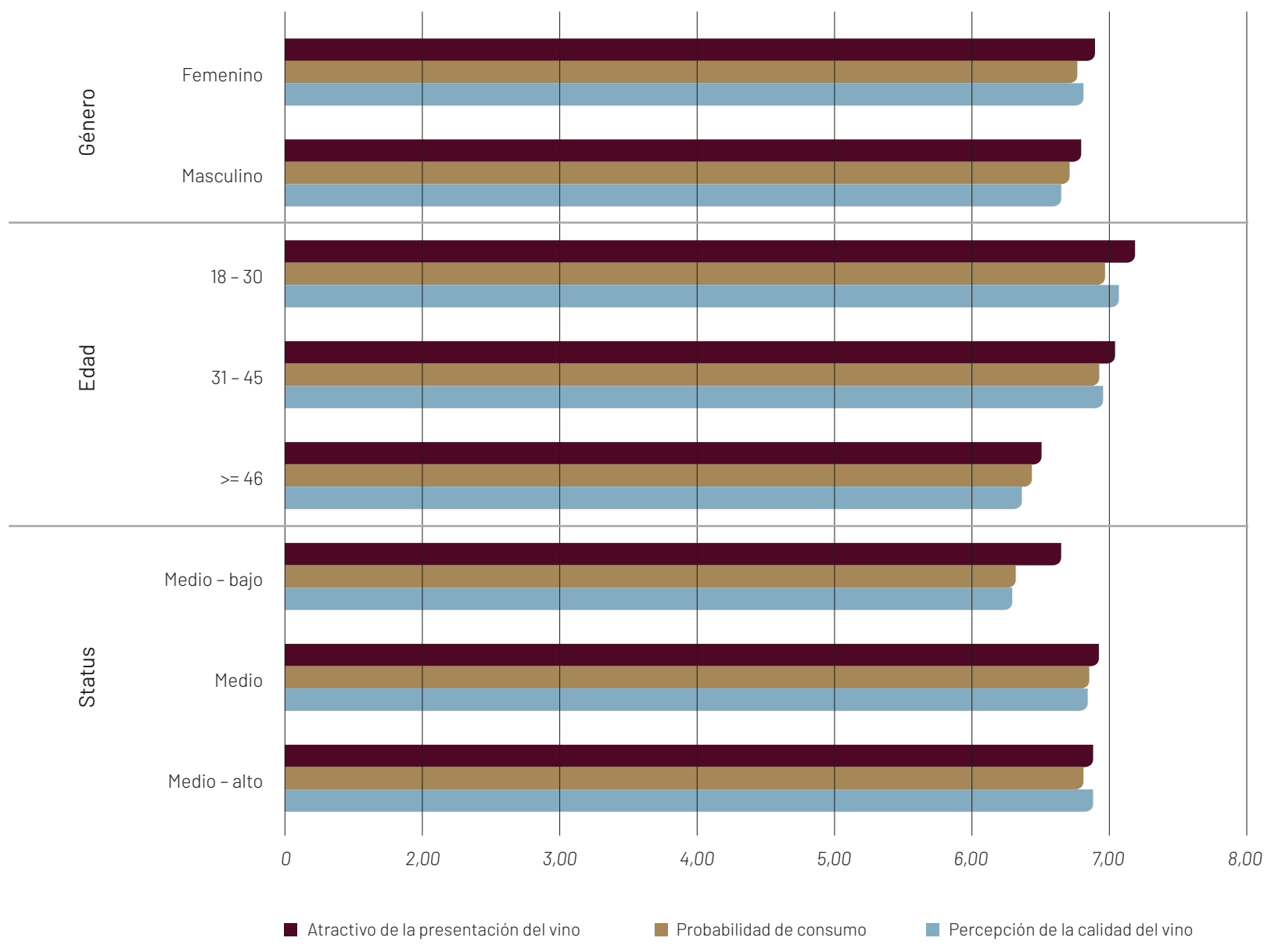

Influencia del atractivo de la presentación de los vinos en la percepción de calidad e intención de consumo 
Según el género, las mujeres muestran mayores puntuaciones que los hombres en estas variables. No obstante, las diferencias no son significativas. Así, la puntuación media en el caso de las mujeres es de 6,89 al valorar el atractivo de la presentación. La media en el caso de los hombres es de 6,80. Por su parte, la probabilidad de consumo media es de 6,76 para las mujeres y de 6,70 para los hombres. Igualmente, al valorar la percepción de calidad, la puntuación media es de 6,81 para las mujeres y de 6,66 para los hombres.

\section{Edad}

Por edad, los más jóvenes muestran mayores puntuaciones que los mayores en las variables analizadas. Al valorar el atractivo de las presentaciones, los jóvenes (entre 18 y 30 años), muestran una puntuación media de 7,19. En el caso de los consumidores con una edad comprendida entre los 31 y 40 años, la puntuación es de 7,05 y de 6,50 en los mayores de 45 años. La probabilidad de consumo de los jóvenes de entre 18 y 30 años es de 6,97, de 6,93 en los consumidores de entre 31 a 40 años, y de 6,44 en los mayores de 45 . Respecto a la percepción de calidad del vino, en el caso de los más jóvenes la puntuación media es de 7,07, de 6,95 en los consumidores de entre 31 a 40 años, y de 6,37 en los mayores de 45 .

\section{Estatus socioeconómico}

Según el estatus, en comparación con aquellos que declaran tener unos ingresos iguales o superiores a la media, los que declaran tener ingresos por debajo de la media se caracterizan por menores puntuaciones al valorar el grado de atractivo, la probabilidad de consumo y la percepción de calidad del producto. Así, los de menor estatus valoran el atractivo de los vinos con una puntuación media de 6,65, mientras que esta es de 6,92 para los de estatus medio. Respecto a la probabilidad de consumo, los consumidores de menor nivel adquisitivo muestran una puntuación media de 6,32. La puntuación es de 6,86 en los consumidores con un estatus medio. Por último, al valorar la percepción de calidad, la puntuación media es de 6,29 para los de menor estatus y de 6,85 para los de estatus medio. 


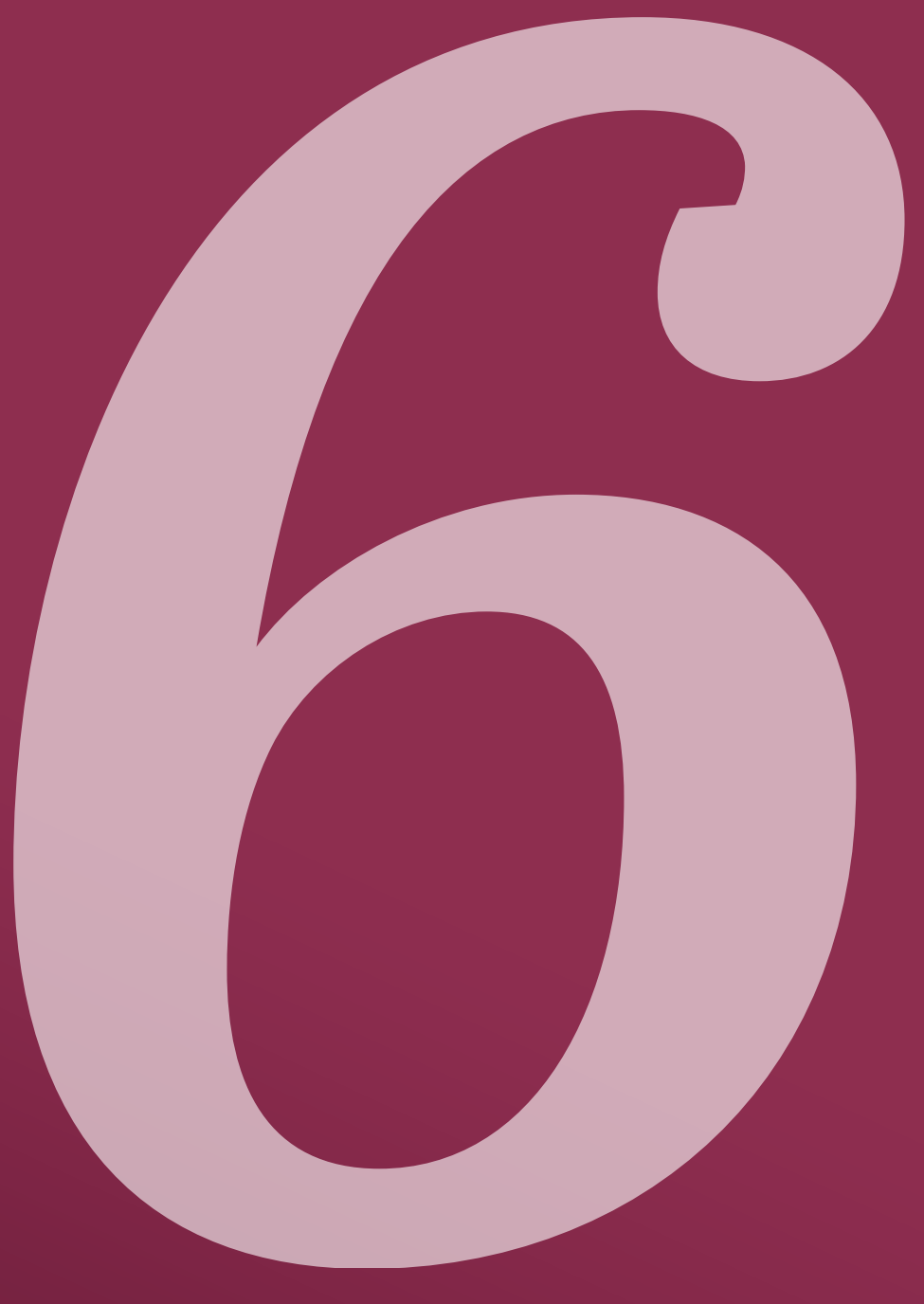

\section{Influencia del diseño de la presentación en el consumo y en la calidad percibida del producto}




\section{Influencia del diseño de la presentación en el consumo y en la calidad percibida del producto}

En el gráfico 3 se representa la puntuación media de las variables probabilidad de consumo, percepción de la calidad del vino y adecuación del diseño a la categoría "vino", en función de si se considera atractiva o no la presentación del producto. Esta variable se ha categorizado en dos niveles: atractivo alto para valores iguales o mayores a $7 \mathrm{y}$ atractivo bajo para valores menores a 7 (escala de 1 a 10). En todos los casos se puede observar la gran influencia del atractivo de la presentación.

Cuando la presentación del producto se considera atractiva, la puntuación media en la variable probabilidad de consumo de un vino (escala de 1 a 10) es de 7,97, mientras que cuando la presentación del producto se considera poco atractiva, la probabilidad de consumo baja a solo 4,67.

De igual forma se comporta la percepción de la calidad del vino. Cuando la presentación del producto se considera atractiva, la puntuación media en la variable "percepción de calidad" es de 7,95, mientras que cuando la presentación del producto se considera poco atractiva, la percepción de calidad es de 4,70.

También se observa cómo el atractivo de la presentación del producto afecta claramente a la consideración de si el diseño es apropiado para un producto de esta categoría, vino. Cuando la atractividad del diseño es baja, la adecuación del diseño es de 4,68. Cuando es alta, su puntuación media es de 8,16. 
Gráfico 3. Intención de consumo, diseño adecuado a la categoría y calidad percibida en función de lo atractivo de la presentación

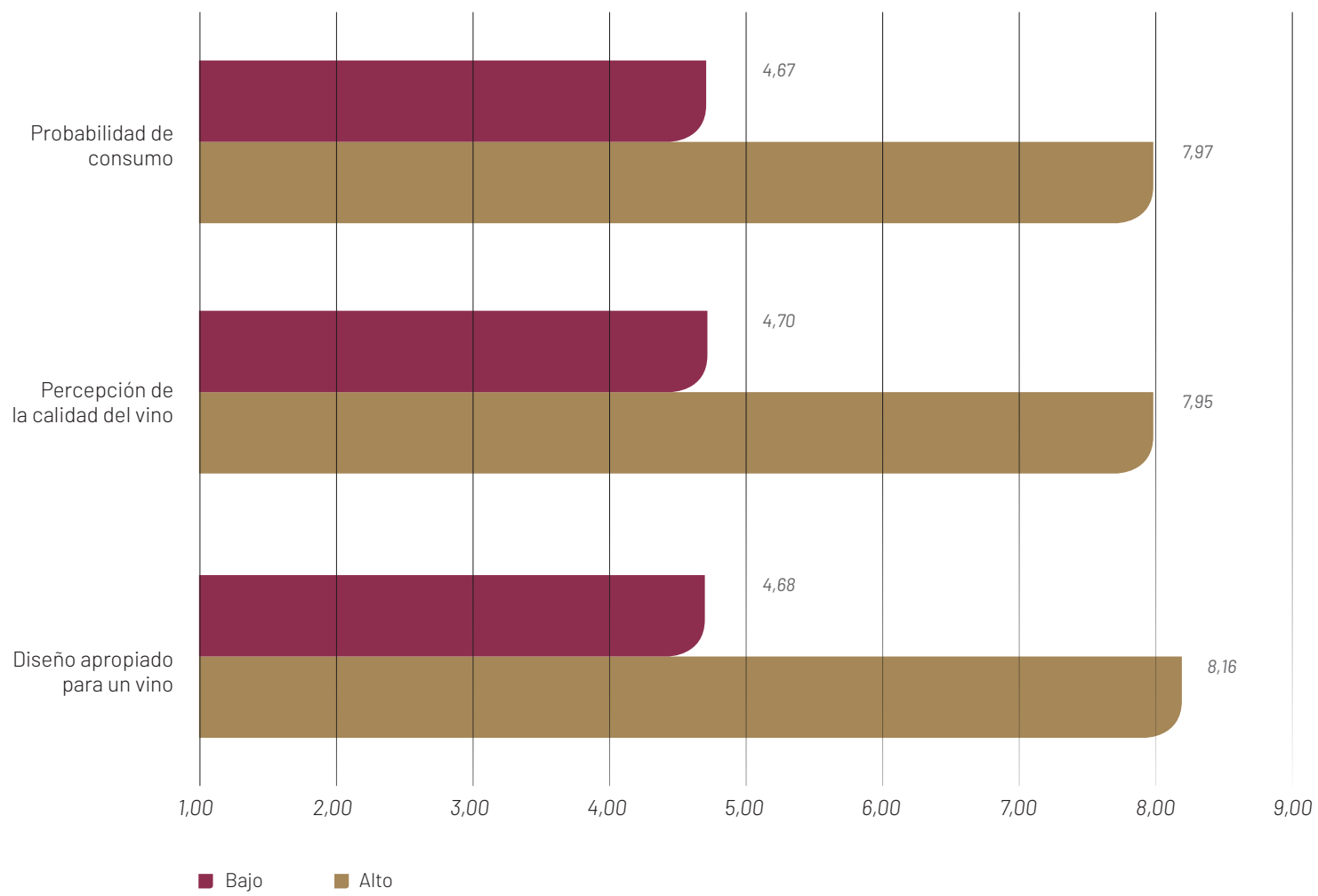

Los datos obtenidos de las declaraciones de la muestra de consumidores ante la visualización de un conjunto variado de tipologías de presentaciones de vino, confirman con rotundidad la hipótesis planteada. El atractivo de la presentación del producto influye en la intención de consumo del vino, en la percepción de su calidad y en la valoración acerca de si el diseño se adecua o no a la categoría del producto. 


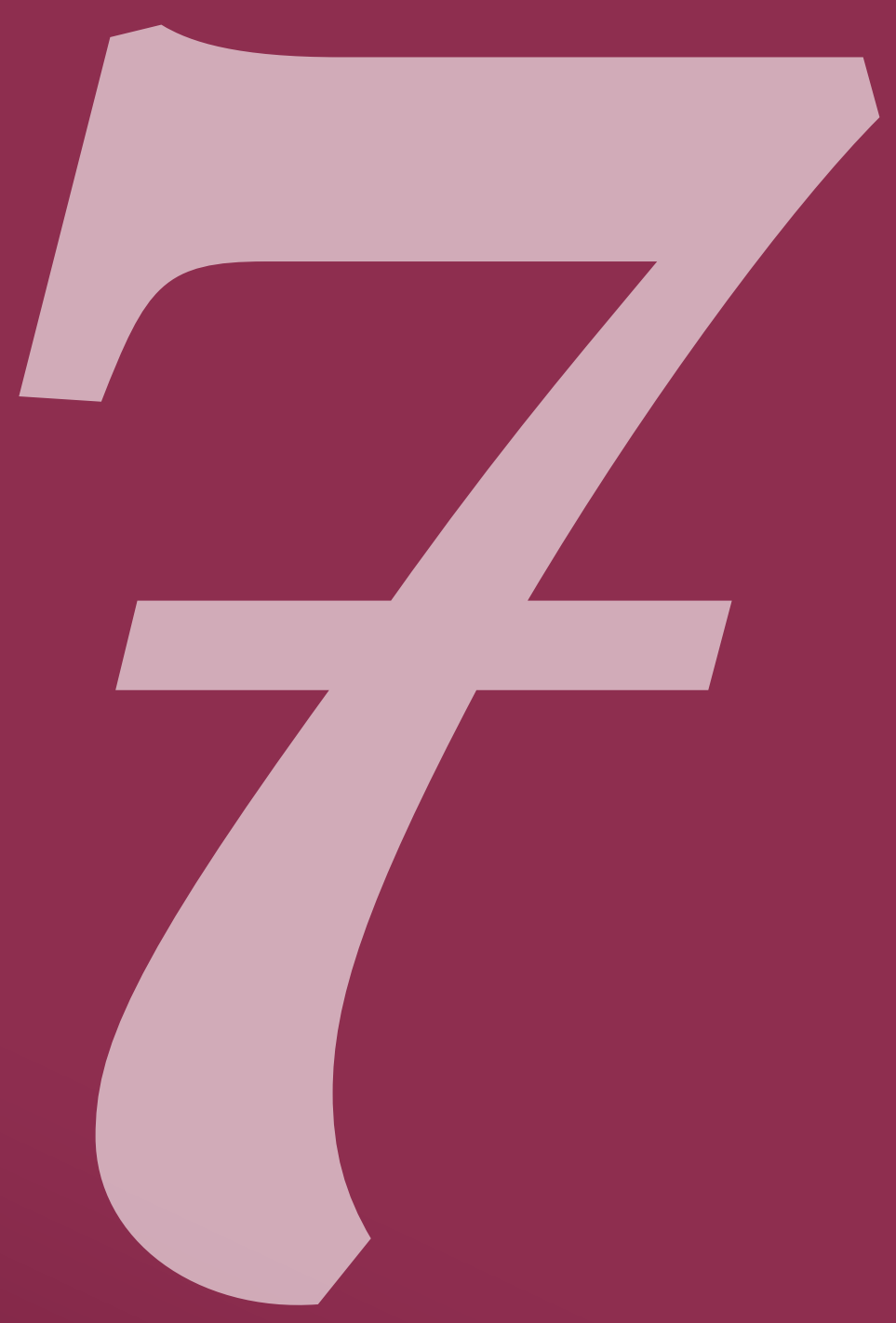

\section{Variables moderadoras de las relaciones entre el} atractivo de la presentación y las variables intención de consumo, percepción de calidad y pertenencia a categoría 


\section{Variables moderadoras de las relaciones entre el atractivo de la presentación y las variables intención de consumo, percepción de calidad y pertenencia a categoría}

En este apartado se analiza en qué medida la experiencia previa con la marca, la frecuencia de consumo, el género, la edad y el nivel adquisitivo, moderan la relación entre el atractivo y las variables intención de consumo, percepción de calidad o pertenencia a categoría.

Gráfico 4. Influencia del atractivo de la presentación en la intención de consumo
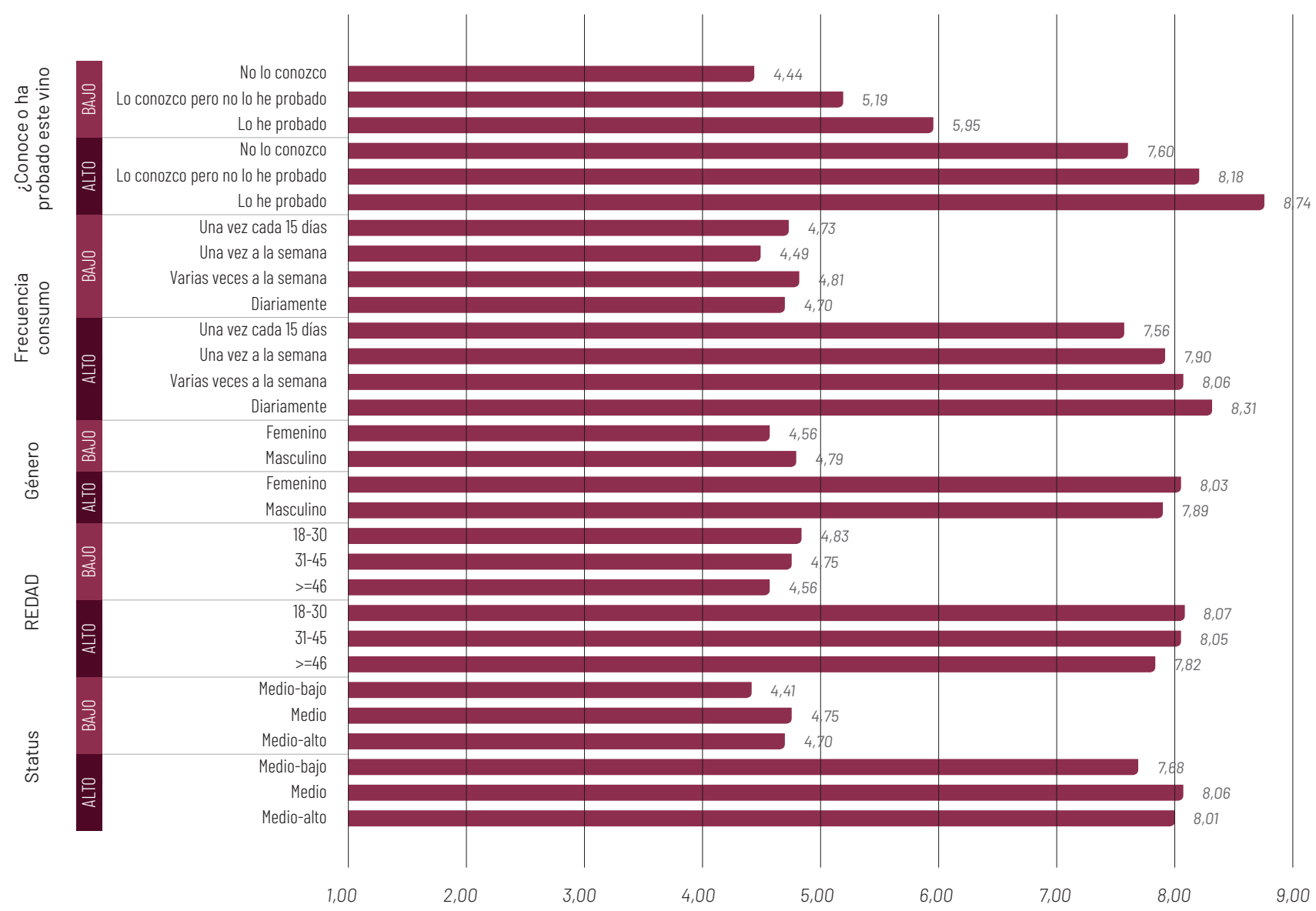
Como puede observarse en el gráfico 4 y en las tablas siguientes, la experiencia previa con la marca, la edad y el estatus socioeconómico no moderan la relación entre el atractivo y la intención o probabilidad de consumo. Es decir, la intención de consumo (según el atractivo de la presentación) no aumenta ni disminuye por el efecto de estas variables. Sin embargo, las variables frecuencia de consumo y género sí moderan esta relación.

En los gráficos 5 y 6 y en las tablas siguientes también se observa que, al igual que sucede en el caso anterior, las variables frecuencia de consumo y género moderan las relaciones entre atractivo del producto y percepción de calidad, y entre atractivo de producto y adecuación del diseño a la categoría vino. Por el contrario, la experiencia previa con la marca, la edad y el estatus socioeconómico no afectan a ninguna de las dos relaciones.
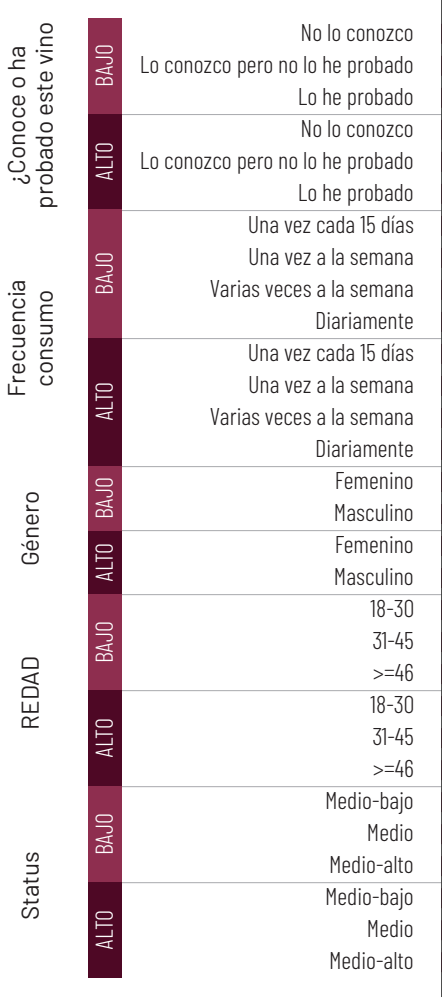

Gráfico 5. Influencia del atractivo de la presentación en la percepción de calidad

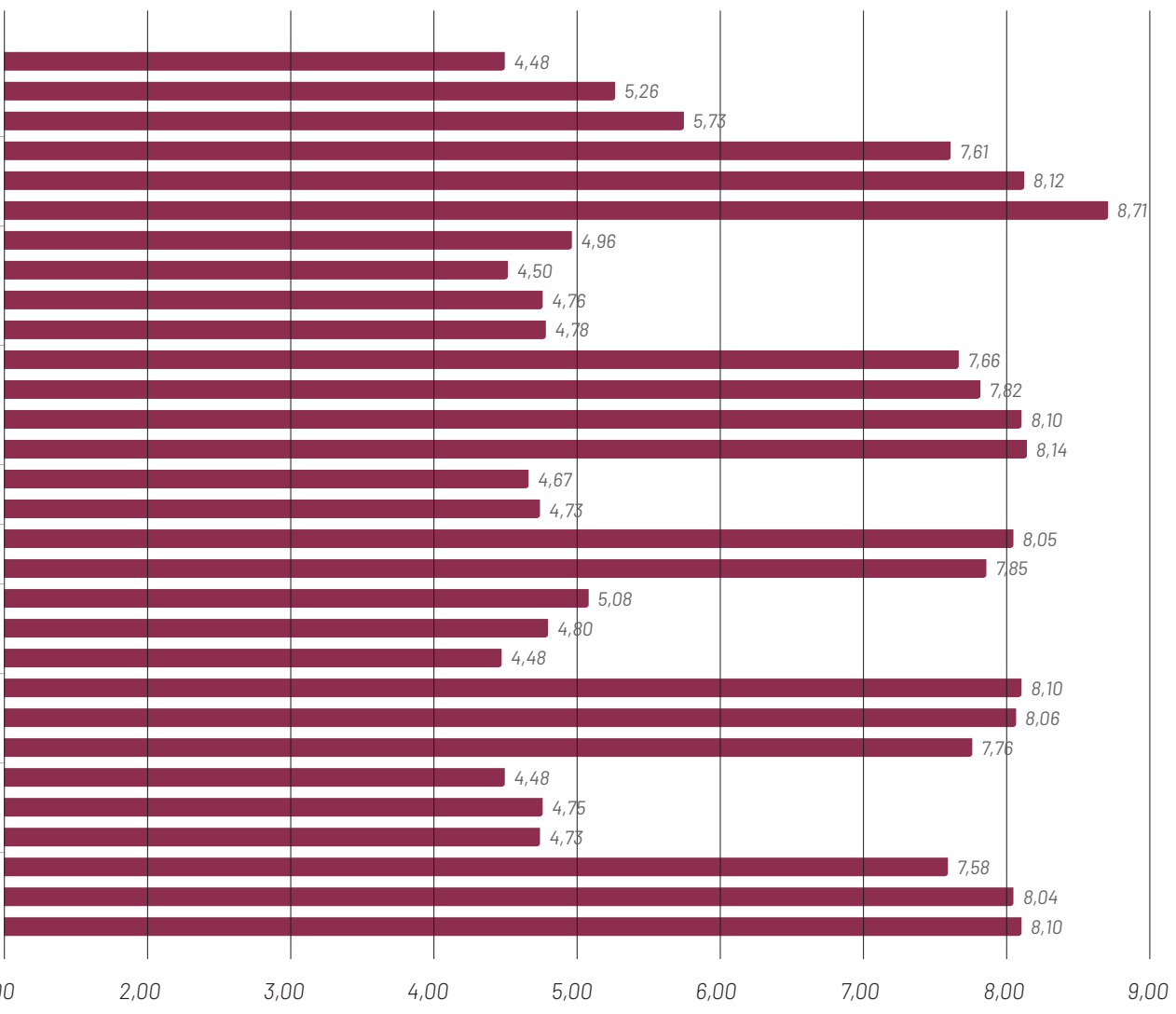

Influencia del atractivo de la presentación de los vinos en la percepción de calidad e intención de consumo 
Gráfico 6. Influencia del atractivo en la valoración de la presentación como adecuada a la categoría

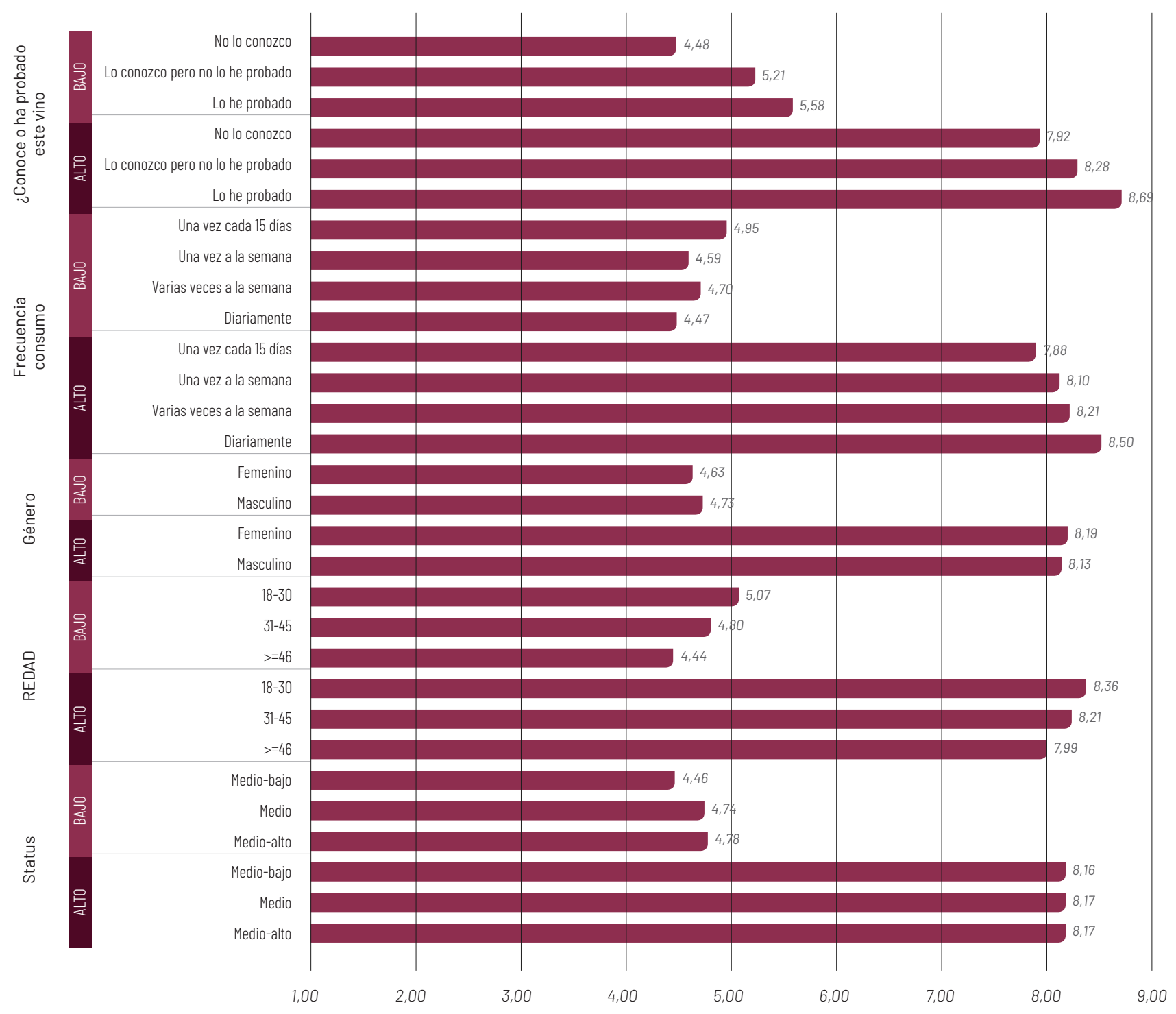




\section{Experiencia previa con la marca}

En cuanto al efecto del conocimiento previo del vino en la relación entre el atractivo del producto y la probabilidad de consumo, se observó que, independientemente del atractivo de la presentación del producto, la probabilidad de consumo es mayor entre los que tienen experiencia previa con el vino.

De esta forma, como se detalla en la tabla 4, cuando la presentación del vino no es atractiva, los que no conocen el vino muestran menor probabilidad de consumo $(4,44)$ que los que lo conocen $(5,19)$ y lo han probado $(5,95)$. De igual forma, cuando la presentación del vino es atractiva, los que no conocen el vino muestran menos probabilidad de consumo $(7,60)$ que los que lo conocen $(8,18)$ y lo han probado $(8,74)$.

Por tanto, conocer el vino afecta a la mayor intención de consumo independientemente de si el diseño del producto es atractivo o no.

Tabla 4. Moderación de la experiencia previa con la marca según atractivo de la presentación

\begin{tabular}{llrrr}
\multirow{2}{*}{ Atractivo } & ¿Conoce o ha probado este vino? & $\begin{array}{r}\text { Probabilidad } \\
\text { de consumo }\end{array}$ & $\begin{array}{r}\text { Percepción } \\
\text { de la calidad } \\
\text { del vino }\end{array}$ & $\begin{array}{r}\text { Diseño } \\
\text { apropiado } \\
\text { para un vino }\end{array}$ \\
\hline \multirow{3}{*}{ Bajo } & No lo conozco & 4,44 & 4,48 & 4,48 \\
\cline { 2 - 5 } & Lo conozco pero no lo he probado & 5,19 & 5,26 & 5,21 \\
\cline { 2 - 5 } & Lo he probado & 5,95 & 5,73 & 5,58 \\
\hline \multirow{3}{*}{ Alto } & No lo conozco & 7,60 & 7,61 & 7,92 \\
\cline { 2 - 5 } & Lo conozco pero no lo he probado & 8,18 & 8,12 & 8,28 \\
\cline { 2 - 5 } & Lo he probado & 8,74 & 8,71 & 8,69 \\
\hline
\end{tabular}

Lo mismo sucede con respecto a la percepción de calidad del vino y a la valoración del diseño como adecuado para la categoría vino. A medida que se tiene mayor conocimiento del vino, mayor es la percepción de calidad del producto y más adecuada se considera la presentación del vino a la categoría, independientemente del atractivo del producto. 
En cuanto al efecto de la edad del consumidor en la relación entre el atractivo del producto y la probabilidad de consumirlo, se observó que, independientemente del atractivo de la presentación del producto, la probabilidad de consumo es mayor a medida que el consumidor es más joven.

Tabla 5. Moderación de la edad según atractivo de la presentación

\begin{tabular}{|c|c|c|c|c|}
\hline Atractivo & Edad & $\begin{array}{r}\text { Probabilidad de } \\
\text { consumo }\end{array}$ & $\begin{array}{l}\text { Percepción de la } \\
\text { calidad del vino }\end{array}$ & $\begin{array}{r}\text { Diseño apropiado } \\
\text { para un vino }\end{array}$ \\
\hline \multirow{3}{*}{ Bajo } & $18-30$ & 4,83 & 5,08 & 5,07 \\
\hline & $31-45$ & 4,75 & 4,80 & 4,80 \\
\hline & $>=4.6$ & 4,56 & $4,4,8$ & $4,4,4$ \\
\hline \multirow{3}{*}{ Alto } & $18-30$ & 8,07 & 8,10 & 8,36 \\
\hline & $31-45$ & 8,05 & 8,06 & 8,21 \\
\hline & $>=4,6$ & 7,82 & 7,76 & 7,99 \\
\hline
\end{tabular}

Lo mismo sucede con respecto a la percepción de calidad del vino y a la valoración del diseño como adecuado para la categoría vino. A medida que el consumidor es más joven, mayor es la percepción de calidad del producto y más adecuada se considera la presentación del producto a la categoría, independientemente del atractivo del producto.

Estatus socioeconómico

En cuanto al efecto del estatus socioeconómico en la relación entre el atractivo del producto y la probabilidad de consumirlo, se observó que, independientemente del atractivo de la presentación del producto, la probabilidad de consumo es mayor en la población con un estatus socioeconómico medio o medio-alto que en aquella con un estatus socioeconómico medio-bajo.

Como se observa en la tabla 6, cuando la presentación del vino no es atractiva, los consumidores de estatus medio $(4,75)$ muestran más probabilidad de consumo que los de mayor estatus $(4,70)$ y que los de estatus bajo $(4,41)$. De igual forma, cuando la presentación del vino es atractiva, los de estatus medio $(8,06)$ 
muestran más probabilidad de consumo que los de mayor estatus $(8,01)$ y que los de estatus bajo $(7,68)$. Por tanto, el nivel adquisitivo del consumidor afecta igualmente en la intención de consumo independientemente del atractivo del producto.

Tabla 6. Moderación del estatus socioeconómico según atractivo de la presentación

\begin{tabular}{llrrr}
\multirow{2}{*}{ Atractivo } & Status & $\begin{array}{r}\text { Probabilidad } \\
\text { de consumo }\end{array}$ & $\begin{array}{r}\text { Percepción de la } \\
\text { calidad del vino }\end{array}$ & $\begin{array}{r}\text { Diseño apropiado } \\
\text { para un vino }\end{array}$ \\
\hline \multirow{2}{*}{ Bajo } & Medio-bajo & 4,41 & 4,48 & 4,46 \\
\cline { 2 - 5 } & Medio & 4,75 & 4,75 & 4,74 \\
\cline { 2 - 5 } & Medio-alto & 4,70 & 4,73 & 4,78 \\
\hline \multirow{2}{*}{ Alto } & Medio-bajo & 7,68 & 7,58 & 8,16 \\
\cline { 2 - 5 } & Medio & 8,06 & 8,04 & 8,17 \\
\cline { 2 - 5 } & Medio-alto & 8,01 & 8,10 & 8,17 \\
\hline
\end{tabular}

Algo muy similar sucede con respecto a la percepción de calidad del vino y a la valoración del diseño como adecuado para la categoría vino. Aquellos consumidores con un nivel adquisitivo medio o medio alto perciben el producto como de mayor calidad y consideran que su diseño se ajusta más a la categoría vino, que los consumidores con un nivel adquisitivo bajo.

\section{Frecuencia de consumo}

En cuanto al efecto de la frecuencia de consumo en la relación entre el atractivo del producto y la probabilidad de consumirlo, se observó que ante diseños poco atractivos del producto, los que se caracterizan por un bajo consumo (una vez cada 15 días) muestran prácticamente la misma probabilidad de consumir el producto $(4,73)$ que los que consumen vino diariamente $(4,70)$. Mientras que, ante diseños atractivos del producto los que consumen diariamente indican mayor probabilidad de consumo $(8,31)$ que los de menor frecuencia de consumo $(7,56)$. Por tanto, los consumidores frecuentes "premian" las presentaciones atractivas en mayor medida que los de bajo consumo. 
Tabla 7. Moderación de la frecuencia de consumo o según atractivo de la presentación

\begin{tabular}{|c|c|c|c|c|}
\hline Atractivo & Frecuencia consumo & $\begin{array}{r}\text { Probabilidad } \\
\text { de consumo }\end{array}$ & $\begin{array}{r}\text { Percepción } \\
\text { de la calidad } \\
\text { del vino }\end{array}$ & $\begin{array}{r}\text { Diseño } \\
\text { apropiado } \\
\text { para un vino }\end{array}$ \\
\hline \multirow{4}{*}{ Bajo } & Una vez cada 15 días & 4,73 & 4,96 & 4,95 \\
\hline & Una vez a la semana & 4,49 & 4,50 & 4,59 \\
\hline & Varias veces a la semana & 4,81 & 4,76 & 4,70 \\
\hline & Diariamente & 4,70 & 4,78 & 4,47 \\
\hline \multirow{4}{*}{ Alto } & Una vez cada 15 días & 7,56 & 7,66 & 7,88 \\
\hline & Una vez a la semana & 7,90 & 7,82 & 8,10 \\
\hline & Varias veces a la semana & 8,06 & 8,10 & 8,21 \\
\hline & Diariamente & 8,31 & 8,14 & 8,50 \\
\hline
\end{tabular}

De forma similar, como se contrasta en la tabla 7, en las presentaciones consideradas atractivas por los consumidores, la percepción de calidad y la adecuación del diseño a la categoría vino aumentan a medida que la frecuencia de consumo es mayor. No sucede lo mismo cuando la presentación del producto es considerada poco atractiva. En este caso, aquellos consumidores con menor frecuencia de consumo (cada 15 días) perciben los productos como de mayor calidad y valoran su presentación como más adecuada a la categoría vino, en comparación a los consumidores más habituales. Los consumidores con menor frecuencia de consumo, parecen mostrar una valoración menos exigente que los de mayor frecuencia de consumo. 


\section{Género}

En cuanto a la moderación del género en la relación entre el atractivo del producto y la probabilidad de consumirlo, se observó que ante diseños poco atractivos del producto, las mujeres muestran menor intención de consumo $(4,25)$ que los hombres $(4,57)$. Mientras que, ante diseños atractivos del producto las mujeres manifiestan mayor probabilidad de consumo $(8,10)$ que los hombres (7,70). Por tanto, en comparación con los hombres, las mujeres "premian" las presentaciones atractivas y "penalizan" los diseños poco atractivos.

De igual forma, como se contrasta en la tabla 8, las mujeres valoran los productos con una presentación atractiva como productos de mayor calidad y con un diseño más adecuado a la categoría vino. Mientras que, cuando el diseño del producto no es atractivo, las mujeres lo perciben como de menor calidad y con un diseño menos apropiado a la categoría vino.

Tabla 8. Moderación del género según atractivo de la presentación

\begin{tabular}{llrrr}
\multirow{2}{*}{ Atractivo } & Género & $\begin{array}{r}\text { Probabilidad de } \\
\text { consumo }\end{array}$ & $\begin{array}{r}\text { Percepción de la } \\
\text { calidad del vino }\end{array}$ & $\begin{array}{r}\text { Diseño apropiado } \\
\text { para un vino }\end{array}$ \\
\hline \multirow{2}{*}{ Bajo } & Femenino & 4,56 & 4,67 & 4,63 \\
\cline { 2 - 5 } & Masculino & 4,79 & 4,73 & 4,73 \\
\hline \multirow{2}{*}{ Alto } & Femenino & 8,03 & 8,05 & 8,19 \\
\cline { 2 - 5 } & Masculino & 7,89 & 7,85 & 8,13 \\
\hline
\end{tabular}

En las mujeres, la percepción de calidad y la consideración del diseño como adecuado a la categoría se ven más afectadas por el diseño de la presentación del vino que en los hombres. 


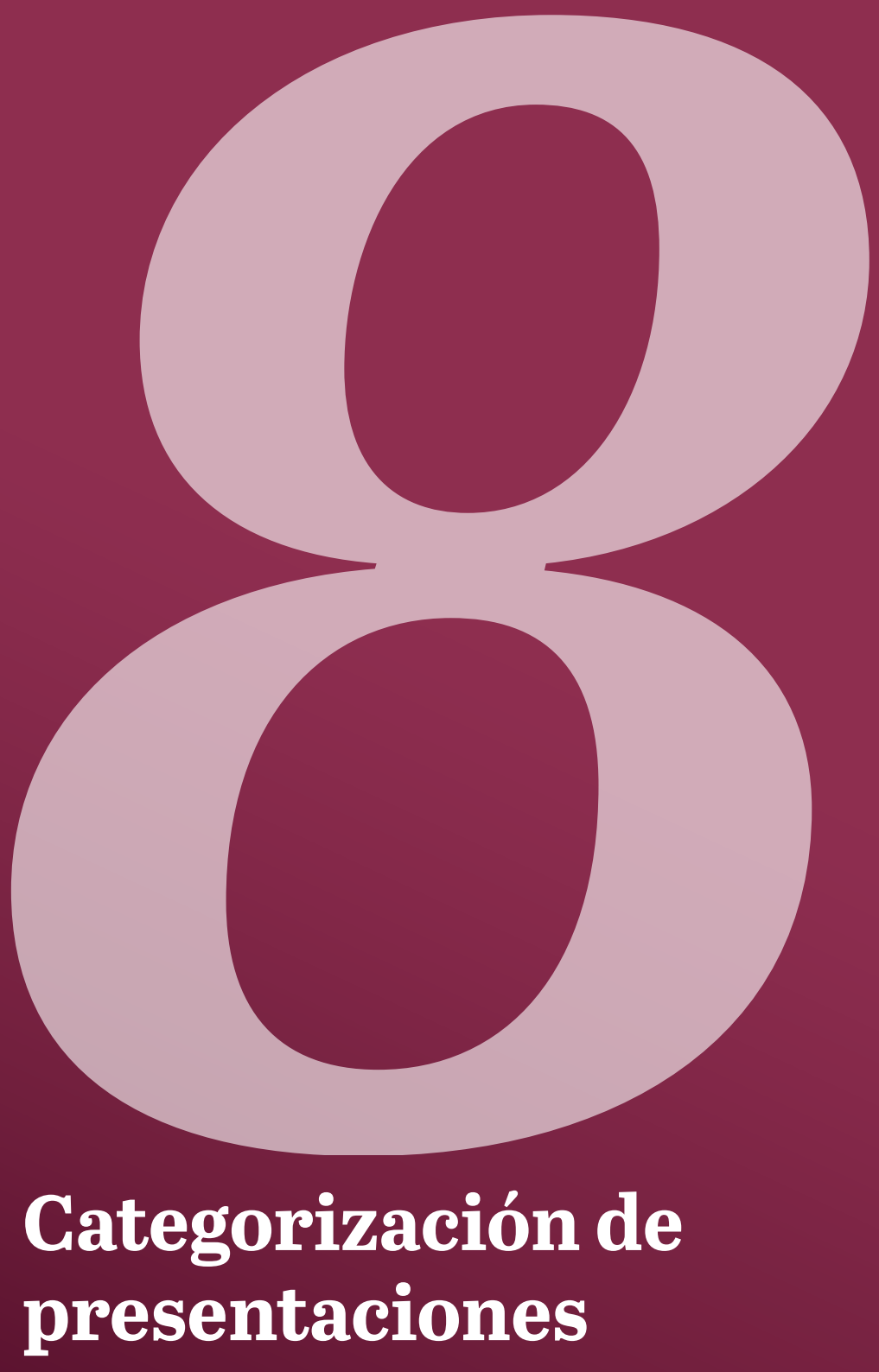




\section{Categorización de presentaciones}

\subsection{Tipologías de diseño}

Con objeto de categorizar las 28 presentaciones de vino utilizadas en la investigación, se solicitó a un grupo de expertos en diseño y/o comunicación publicitaria la valoración de las mismas. La gran variedad de tipologías de diseño utilizadas que representan al conjunto de la oferta de vinos de Canarias, permitió clasificarlas atendiendo a la valoración que hicieron los diseñadores según los siguientes criterios de diseño:

- Transgresor vs. Convencional.

- Emocional vs. Frío.

- Moderno vs. Anticuado.

- Diseño cuidado vs. Diseño descuidado.

- $\quad$ Elegante, fino vs. Vulgar, corriente.

- Coherente con categoría vino vs. Incoherente con categoría vino.

Según la puntuación obtenida en los seis criterios anteriores, las presentaciones de cada vino fueron agrupadas en las 5 categorías siguientes:

- Transgresor en categoría (5 presentaciones).

- Transgresor fuera de categoría (3 presentaciones).

- Tradicional con diseño cuidado (9 presentaciones).

- Tradicional fuera de categoría (6 presentaciones).

- Tradicional poco cuidado (5 presentaciones).

En el gráfico 7 se detallan las puntuaciones medias de cada categoría de vino en cada uno de los 6 criterios según los cuales fueron valorados. Se utilizó una escala de 1 a 7 puntos donde el 4 era el punto medio. 
Gráfico 7. Tipologías de diseño según valoraciones de diseñadores

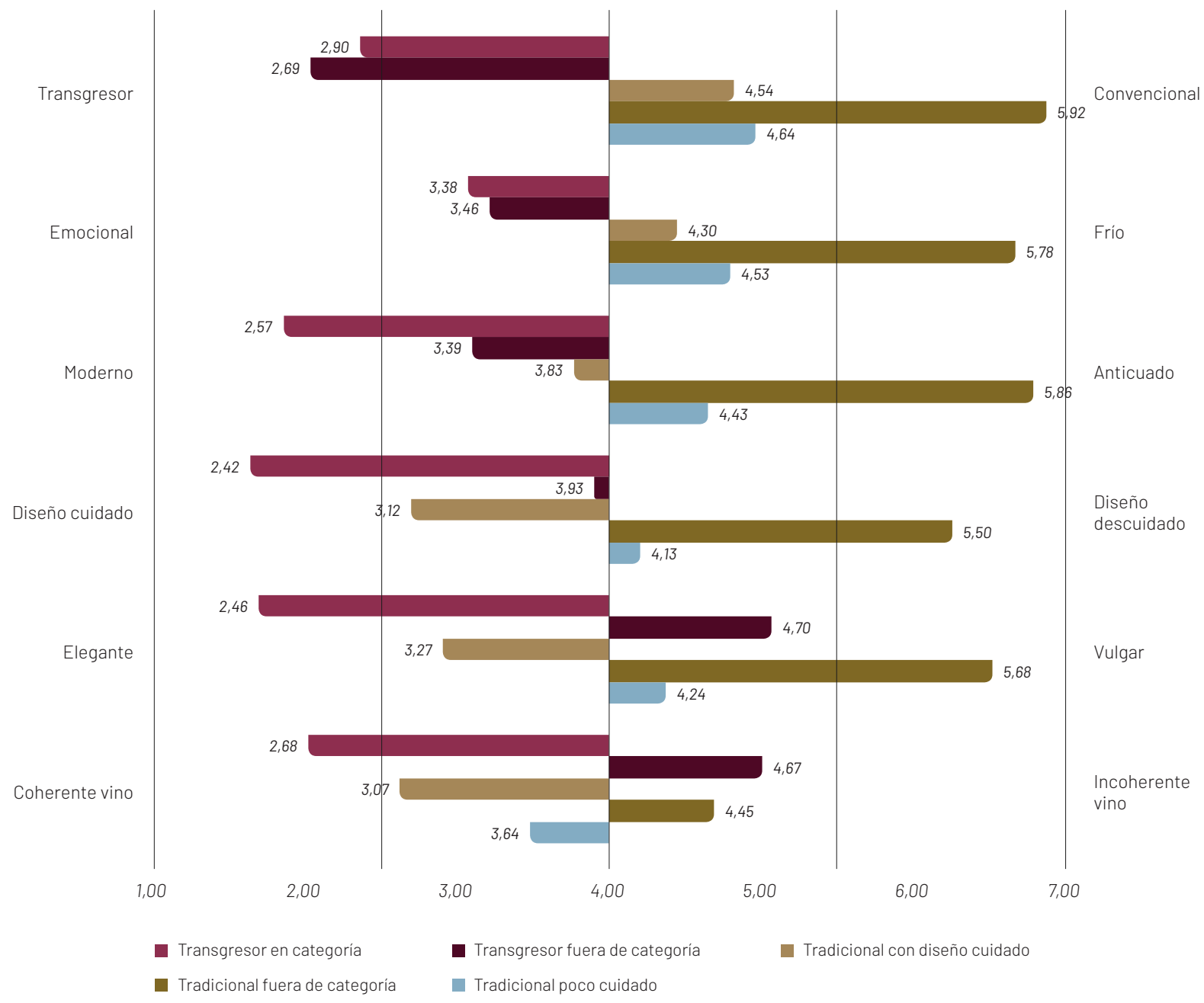

La tipología “Transgresor en categoría” se caracteriza por tener un diseño transgresor, emocional, moderno, un diseño cuidado, elegante y todo ello manteniendo la coherencia con la categoría vino. En la gráfica pueden observarse las puntuaciones medias de la categoría en cada uno de los criterios. 
Por su parte, el perfil de diseño de la tipología que se ha denominado "Transgresor fuera de categoría" se define como un diseño transgresor, algo emocional, algo moderno, poco cuidado, vulgar e incoherente con la categoría vino. Así, en la escala utilizada obtiene medias de "Transgresor vs. Convencional" en el valor 2,69, en "Emocional vs. Frío" con el valor 3,46, en "Moderno vs. Anticuado" con 3,39; en "Diseño cuidado vs. Diseño descuidado" con 3,93, en "Elegante vs. Corriente" con 4,7 y en "Coherente vs. Incoherente con categoría" en 4,67.

La tipología "Tradicional con diseño cuidado" se caracteriza por tener un diseño convencional, cuidado, algo elegante y algo coherente con la categoría "vino". Concretamente, la media en "Transgresor vs. Convencional" se sitúa en el valor 4,54, en "Emocional vs. Frío" con el valor 4,30, en "Moderno vs. Anticuado" con 3,83; en "Diseño cuidado vs. Diseño descuidado" con 3,12, en "Elegante vs. Corriente" con 3,27 y en "Coherente vs. Incoherente con categoría" en 3,07.

La tipología "Tradicional fuera de categoría" se caracteriza por tener un diseño muy marcado como convencional, frío, anticuado, descuidado, vulgar y algo incoherente con la categoría "vino". En la escala utilizada, la media en "Transgresor vs. Convencional" se sitúa en el valor 5,92, en "Emocional vs. Frío" con el valor 5,78, en "Moderno vs. Anticuado" con 5,86; en "Diseño cuidado vs. Diseño descuidado" con 5,50, en "Elegante vs. Corriente" con 5,68 y en "Coherente vs. Incoherente con categoría" en 4,45.

Finalmente el perfil de la tipología "Tradicional poco cuidado" se caracteriza por tener un diseño algo más moderado que el anterior, pero convencional, frío, algo anticuado, poco cuidado, vulgar y algo coherente con la categoría "vino". En la escala utilizada, la media en "Transgresor vs. Convencional" se sitúa en el valor 4,64, en "Emocional vs. Frío" con el valor 4,53, en "Moderno vs. Anticuado" con 4,43; en "Diseño cuidado vs. Diseño descuidado" con 4,13, en "Elegante vs. Corriente" con 4,24 y en "Coherente vs. Incoherente con categoría" en 3,64. 


\subsection{Valoraciones de las tipologías por los consumidores}

Después de identificar y agrupar cada diseño/presentación de vino según su tipología (definidas a partir de las valoraciones realizadas por los diseñadores), se han analizado las valoraciones realizadas por los consumidores. En el gráfico 8 se describe la puntuación media de cada tipo de diseño de vinos en las variables atractivo, intención de consumo y calidad percibida del producto.

La tipología "Transgresor en categoría" es la que obtiene mayor puntuación en atractivo $(7,32)$, en probabilidad de consumo $(7,12)$ y en percepción de calidad $(7,12)$. En un ranking de valoraciones se sitúa en segundo lugar la tipología "tradicional con diseño cuidado" con una media en atractivo de 7,09, de 7,01 en probabilidad de consumo y de 7,04 en percepción de calidad.

Muy próximo aunque ligeramente por debajo está la tipología “Tradicional poco cuidado" con medias de 7,01 en atractivo, 6,95 en probabilidad de consumo y 6,90 en percepción de calidad.

En cuarto lugar, con valores inferiores a 7, se coloca la tipología "Tradicional fuera de categoría" con una media de 6,8 en atractivo, 6,74 en probabilidad de consumo y de 6,77 en percepción de calidad.

Y finalmente, la tipología “Transgresor fuera de categoría” es la que menor puntuación obtiene, muy alejada de las anteriores: atractivo $(5,27)$, probabilidad de consumo $(5,01)$ y percepción de calidad $(4,96)$.

Las tipologías transgresor en categoría y tradicional con diseño cuidado son las que se asocian a mayor atractivo de la presentación, calidad percibida y alta probabilidad de consumo. La tipología tradicional fuera de categoría muestra valores muy por debajo de los demás en las tres variables analizadas. 
Gráfico 8. Influencia de tipo de diseño en el atractivo, probabilidad de consumo y percepción de calidad según los consumidores
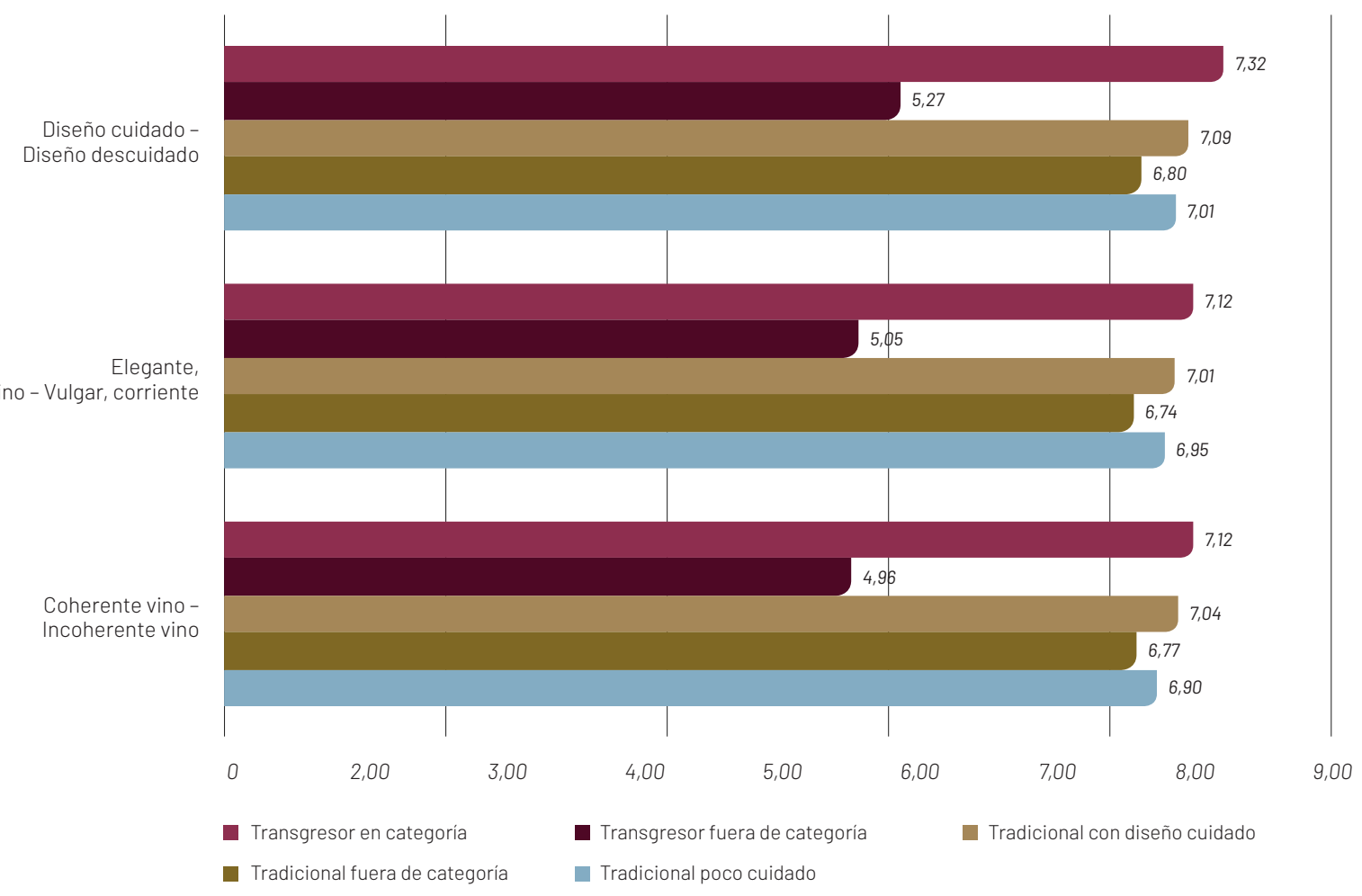


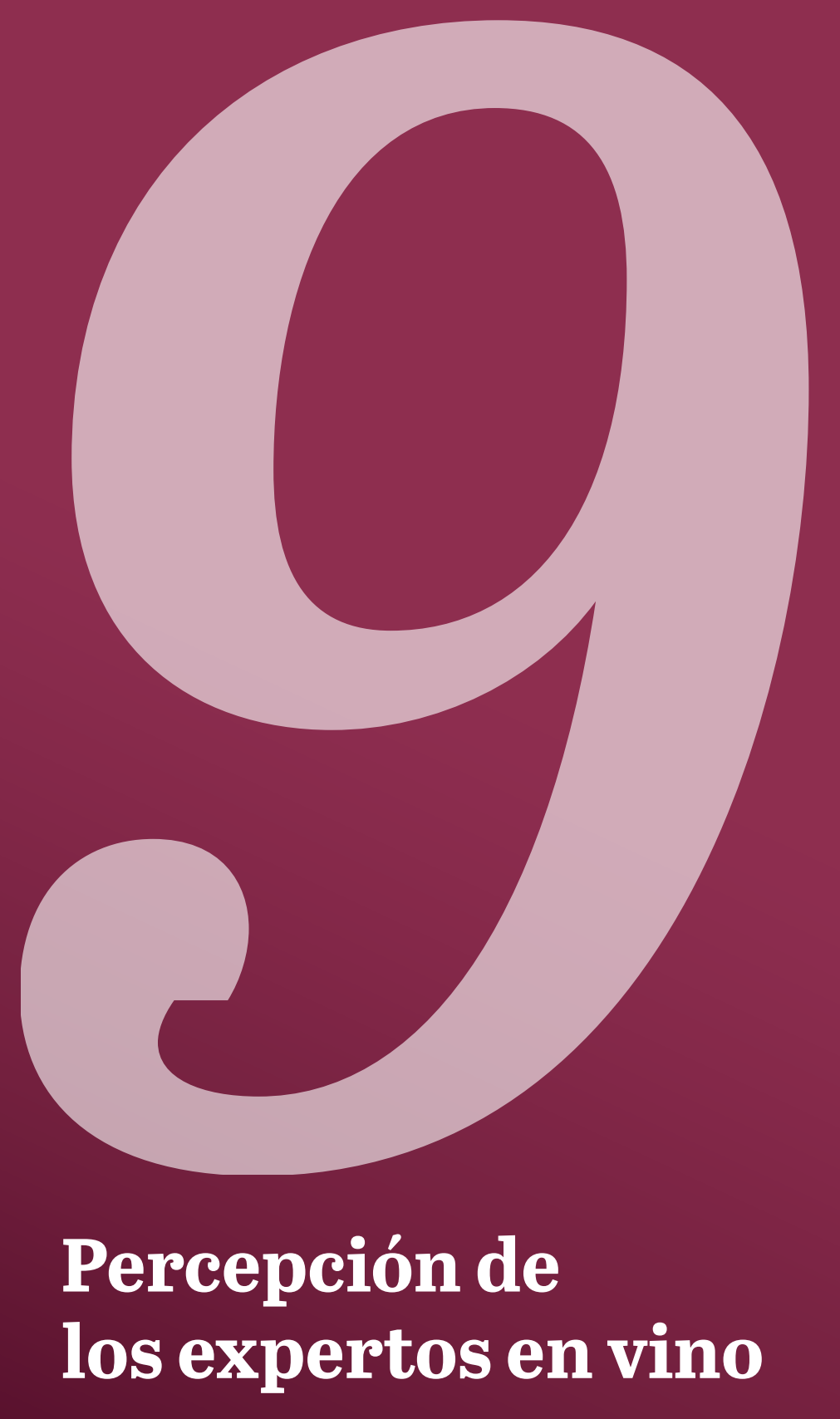




\section{Percepción de los expertos en vino}

En la tabla 9 se compara la valoración que hacen los expertos sobre la calidad de los vinos con la calidad percibida por los consumidores. Esta comparación se analiza para 3 grupos de vinos según la valoración que han hecho los consumidores de su atractivo: bajo, medio y alto.

En la primera columna de la tabla 9 se muestran las puntuaciones medias de las valoraciones que han llevado a cabo los expertos sobre la calidad técnica de los vinos. En la segunda columna se muestran las puntuaciones medias de la calidad percibida por parte de los consumidores y en la última columna se muestra la diferencia de medias entre la valoración de los expertos y la de los consumidores.

Este análisis se llevó a cabo debido a que las conclusiones obtenidas al analizar la valoración de los consumidores podrían estar sesgadas en el caso de que los buenos diseños se correspondieran con buenos vinos. Si bien estos datos parecen indicar que aquellos vinos de mejor calidad suelen presentarse en envases con un diseño más atractivo (y al contrario con los de menor calidad), también se constata que el diseño o presentación de los vinos afecta a la percepción de calidad del producto.

Cuando la presentación de los vinos es considerada por los consumidores como poco atractiva, estos infravaloran la calidad del producto en comparación con la valoración técnica de los expertos, conocedores de los vinos presentados a valoración. Al contrario sucede cuando la presentación de los vinos es considerada atractiva. En este caso, los consumidores sobrevaloran la calidad del producto en comparación con el juicio de los expertos. Es decir, un diseño poco atractivo penaliza al producto (se infiere que es de menor calidad), mientras que un diseño atractivo lo recompensa al generar expectativas de mejor calidad.

Así, se puede observar en la tabla 9 que en el caso de los vinos con una presentación poco atractiva, los expertos valoran su calidad con una puntuación media de 6,05, mientras que los consumidores los puntúan con un 5,63 (-o,42 puntos de diferencia). De forma contraria, cuando la presentación de los vinos es atractiva, la valoración media de los expertos es de 6,95, mientras que la puntuación media de los consumidores es de 7,43 (+o,48 puntos de diferencia). 
Tabla 9. Comparación de la calidad percibida por los consumidores frente a la calidad "técnica" según los expertos, en función del atractivo del diseño juzgada por los consumidores.

\begin{tabular}{|c|c|c|c|c|}
\hline & & $\begin{array}{l}\text { Opinión } \\
\text { expertos sobre } \\
\text { la calidad } \\
\text { técnica del vino }\end{array}$ & $\begin{array}{l}\text { Percepción calidad } \\
\text { consumidores }\end{array}$ & Diferencia \\
\hline \multirow{3}{*}{$\begin{array}{l}\text { Atractivo } \\
\text { consumidores }\end{array}$} & Bajo & 6,05 & 5,63 & $-0,42$ \\
\hline & Medio & 6,53 & 6,83 & 0,30 \\
\hline & Alto & 6,95 & 7,43 & 0,48 \\
\hline
\end{tabular}




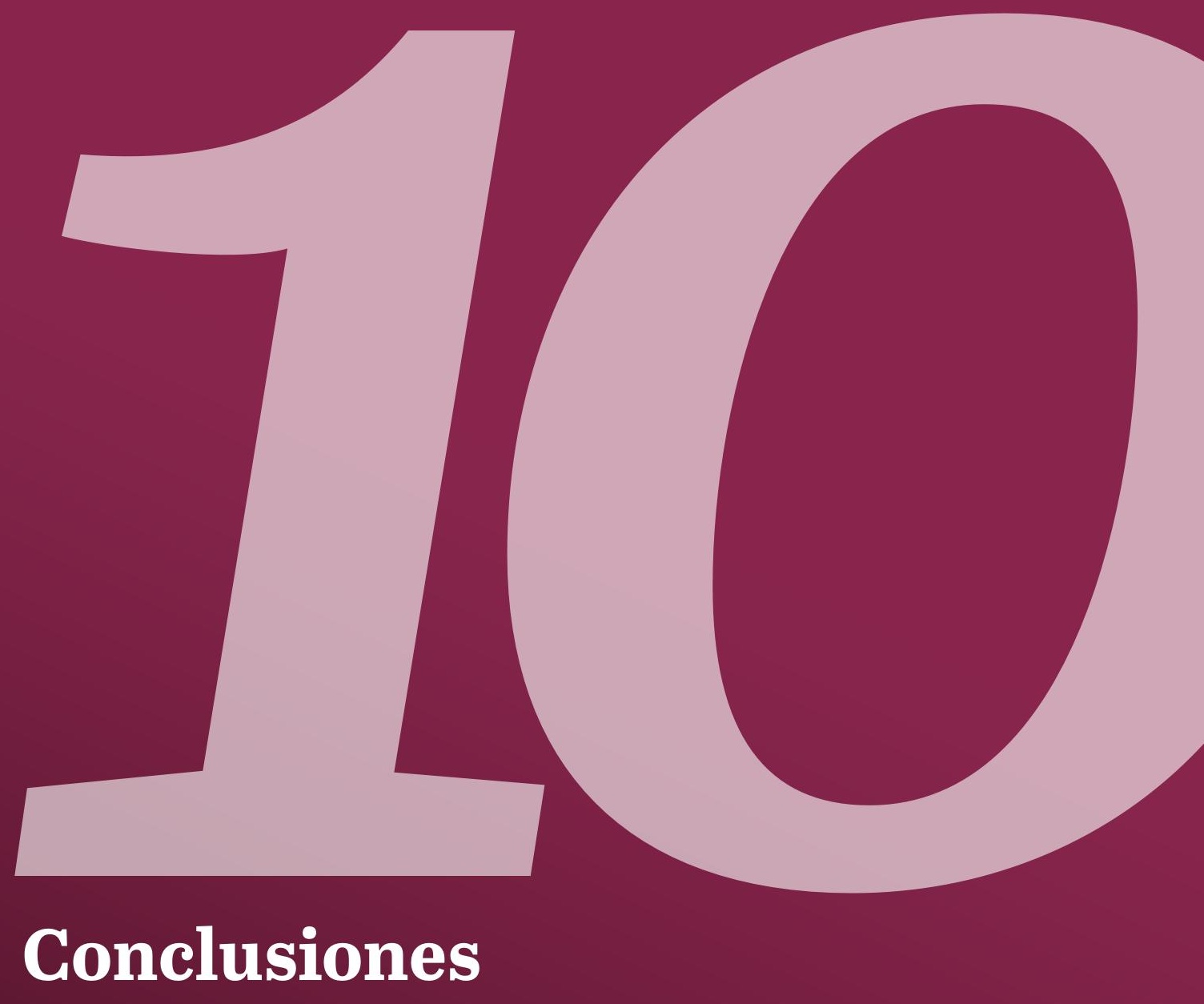




\section{Conclusiones}

El vino es uno de los productos locales agrícolas de mayor importancia en Canarias. Se trata del cultivo con mayor superficie ocupada y contribuye de forma muy importante a la conservación paisajística. Sin embargo, la cuota de mercado de vino local en el consumo de vino en Canarias sigue evidenciando un margen de mejora importante.

En las últimas décadas el sector se ha focalizado, de forma comprensible, en la enología, la viticultura y el análisis sensorial del vino al objeto de mejorar la calidad intrínseca del producto. No obstante, recientemente ha aumentado exponencialmente el interés por lo que se denomina como "psicología del vino", permitiendo que se tenga conciencia de cómo una amplia variedad de factores cognitivos y perceptivos sesgan la percepción del vino y la experiencia con el producto. El diseño de la etiqueta, la botella o la marca son algunos de estos factores.

El vino es un producto complejo por su gran cantidad de características y elementos objetivos y subjetivos que lo componen, que se concreta en una oferta de valor llena de significados, experiencias, valores y deseos realizada por los productores a los consumidores. En este sentido, la elección y evaluación de la calidad del vino realizada por los consumidores se basa principalmente en señales extrínsecas, debido a que las características intrínsecas de un vino sólo pueden ser apreciadas por los consumidores después de su consumo. Las señales extrínsecas no solo afectan a las expectativas de calidad antes de probar el vino, sino que también pueden influir en la percepción de las características una vez que se prueba el vino. Esto está ampliamente demostrado en la literatura (véase, Díaz-Armas et al., 2020; Locksin y Corsi, 2020) y es coherente con los resultados obtenidos en el presente estudio.

Muchos estudios han constatado la importancia del packaging, pues no es un mero elemento que contiene y protege el producto, se trata de un vehículo de comunicación gracias a la información que ofrece del producto y a aspectos como el color, la forma, el diseño o el mensaje. La información emitida por el packaging debe ser coherente con los atributos del producto, ya que cualquier cambio o modificación afectaría a la naturaleza percibida del producto (Zeithaml, 1988; Lockshin \& Corsi, 2012; Lockshin \& Cohen, 2011; Lockshin \& Hall, 2003). 
En su conjunto, el packaging emite una imagen única e integral del producto (Mueller \& Szolnoki, 2010) que permite al consumidor evaluar el producto y modificar la percepción de calidad del mismo (Di Vita, Caracciolo, Brun \& D'Amico, 2019) o la intención de compra (Newman, 2009; Abdullah y Anagreh, 2011). Para ello, la información emitida debe ser fluida, cuidando el grado de elaboración y facilitando la transmisión del mensaje del producto y la marca (Orth \& Crouch, 2014).

Cuando los consumidores observan el diseño del packaging se forman unas expectativas e infieren las características del producto. En consecuencia, si el diseño del envase parece "de calidad", los consumidores generalmente predicen que el producto es de alta calidad y viceversa. En muchos casos, los juicios de valor de los consumidores sobre los productos se basan en el atractivo del envase, por lo que se forma un vínculo entre el atractivo y las decisiones de compra.

En este estudio se ha analizado la influencia del diseño de la presentación del vino en la intención de consumo, la percepción de calidad y la pertenencia a la categoría vino. Para ello se seleccionaron 28 vinos canarios de diferentes islas, teniendo en cuenta la forma de la botella, el formato y estilo de la etiqueta, la denominación de origen, el tipo de vino o el recorrido de la bodega. La imagen de estos vinos fue presentada a 347 personas mayores de 18 años y consumidores. En cada caso debían valorar la calidad percibida en el producto, el conocimiento que tenían del mismo, la probabilidad de consumirlo, el atractivo de la presentación del producto y si se trataba de un diseño apropiado para la categoría vino.

La imagen de los vinos fue evaluada también por 18 profesionales del diseño y la comunicación al objeto de identificar tipologías de diseño más exitosas. Además, un grupo de expertos calificó la calidad técnica de los 28 vinos para poder contrastar este juicio objetivo con el emitido por los consumidores no expertos. 
A continuación, en consonancia con los resultados alcanzados y las aportaciones teóricas, se recogen las principales conclusiones de los resultados del estudio:

a) Valoración global de los vinos analizados según hábitos de consumo y variables sociodemográficas.

Se estudió en qué medida los hábitos de consumo recogidos mediante las variables "conocimiento de la marca" (no lo conozco/ lo conozco / lo he probado) y frecuencia de consumo influyen en la valoración del atractivo del producto, su percepción de calidad y su probabilidad de consumo. Los resultados evidenciaron que, a medida que se tenía mayor conocimiento del producto, las presentaciones de los vinos se valoraban como más atractivas, los productos se juzgaban como de mayor calidad y se manifestaba mayor intención de consumirlos. En el caso de la frecuencia de consumo los resultados siguieron una línea muy similar. Aquellos consumidores que manifestaban una mayor frecuencia de consumo también puntuaron más alto en las tres variables anteriores (atractivo, calidad y probabilidad de consumo).

Es de destacar que la influencia de la experiencia con la marca es más fuerte que la frecuencia de consumo. Tener la marca en la mente, reconocerla y haberla consumido refuerza aún más la percepción de atractivo y la percepción de calidad del vino. Esto conlleva una mayor probabilidad de consumo. Esto quiere decir que las marcas de vino deben trabajar el reconocimiento de sus nombres y la asociación del packaging a su bodega, lo que podría comportar un impulso significativo en sus ventas.

También se analizó cómo las variables sociodemográficas (edad, género y estatus socioeconómico) se relacionaban con las variables anteriores. Los resultados evidenciaron que las mujeres, los jóvenes y las personas de estatus socioeconómico medio-alto valoran las presentaciones de los vinos como más atractivas, perciben mayor calidad en los productos y manifiestan mayor intención de consumirlos. El resto parecen ser más críticos. Estos colectivos además coinciden con los de mayor frecuencia de consumo (Díaz-Armas et al, 2020). 
b) Influencia del diseño de la presentación en la intención de consumo, en la calidad percibida del producto y en la adecuación de su diseño.

Los resultados muestran que cuando el diseño de un packaging es atractivo, los consumidores consideran que el producto es de mayor calidad, manifiestan que la probabilidad de consumirlo es mayor y valoran su diseño como adecuado a la categoría "vinos". Sucede lo contrario cuando el diseño del packaging no es atractivo para el consumidor.

En el caso de la valoración de la calidad del producto, al comparar las puntuaciones entre los expertos y los consumidores, podemos observar un efecto importante. Cuando la presentación de los vinos es considerada por los consumidores como poco atractiva, estos infravaloran la calidad del producto en comparación con la valoración técnica de los expertos. Al contrario sucede cuando la presentación de los vinos es considerada atractiva. En este caso, los consumidores sobrevaloran la calidad del producto en comparación con el juicio de los expertos. Es decir, un diseño poco atractivo penaliza al producto (se infiere que es de menor calidad), mientras que un diseño atractivo lo recompensa al generar expectativas de mejor calidad.

Por tanto, los resultados evidencian la importante influencia del diseño del packaging, más concretamente, de su atractivo, en la probabilidad de consumo y en la percepción de calidad del vino.

\section{c) Calidad objetiva versus calidad percibida}

Un grupo de expertos emitió una valoración técnica y objetiva de la calidad de los vinos estudiados. Este juicio se comparó con la calidad percibida por los consumidores en 3 grupos de vinos según su nivel de atractivo: bajo, medio y alto.

Los datos indicaron que los vinos de mejor calidad suelen presentarse en envases con un diseño más atractivo (y al contrario con los de menor calidad). Es decir, parece que la "profesionalización" del vino conlleva una optimización tanto del producto como del diseño. 
Además, en consonancia con el apartado b) de estas conclusiones, los datos también muestran que el diseño o presentación de los vinos afecta a la percepción de calidad del producto. Cuando la presentación de los vinos es considerada por los consumidores como poco atractiva, estos infravaloran la calidad del producto (en comparación con la valoración técnica de los expertos).

Al contrario sucede cuando la presentación de los vinos es considerada atractiva. En este caso, los consumidores sobrevaloran la calidad del producto en comparación con el juicio de los expertos. Es decir, un diseño poco atractivo penaliza al producto (se infiere que es de menor calidad), mientras que un diseño atractivo lo recompensa al generar expectativas de mejor calidad.

Por tanto, los productores deben hacer énfasis en crear diseños o presentaciones atractivas de los productos para, en primer lugar, evitar que se minusvalore el producto $y$, en segundo lugar, generar expectativas de mayor calidad y ofrecer una mejor propuesta de valor.

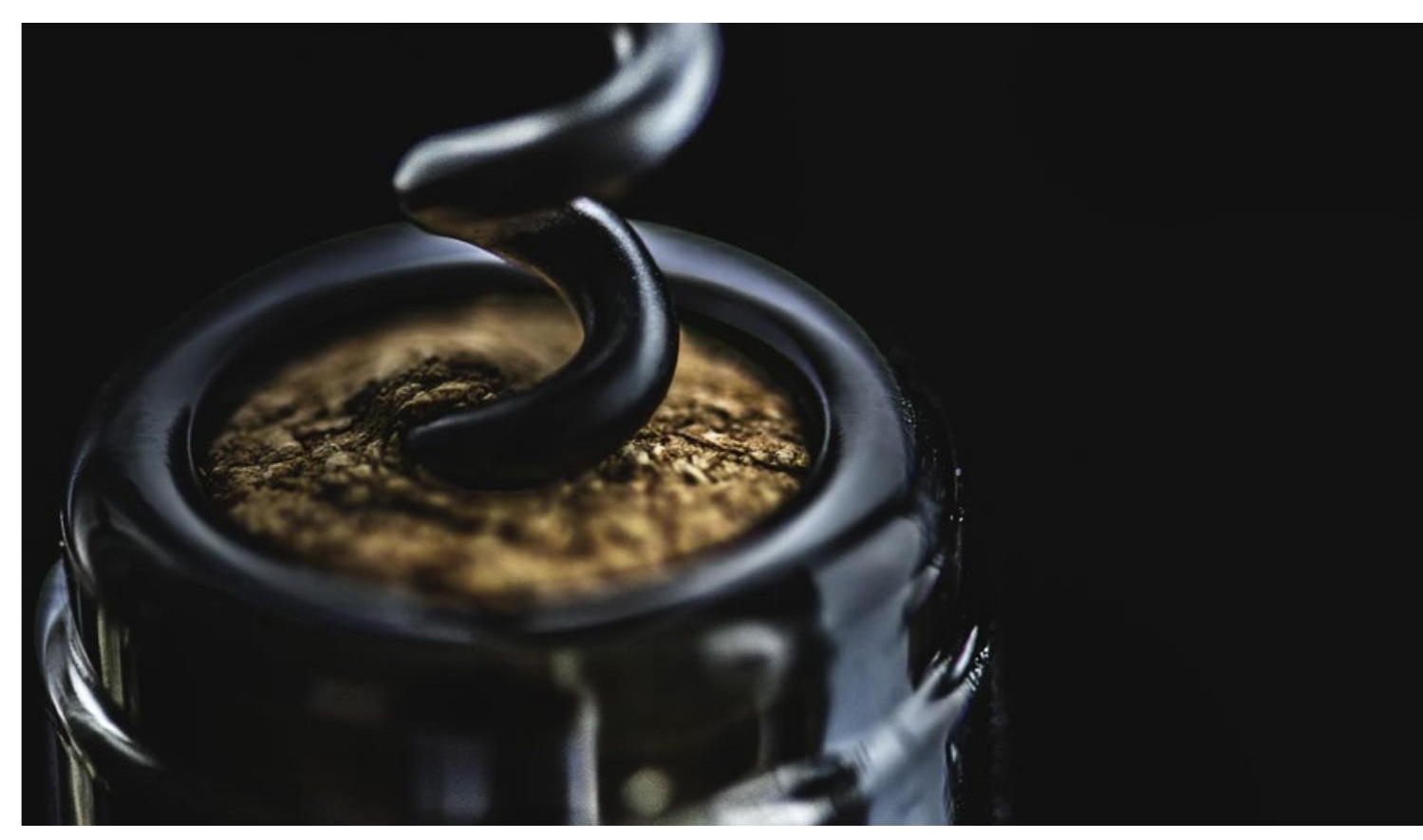

Influencia del atractivo de la presentación de los vinos en la percepción de calidad e intención de consumo 


\section{d) Variables moderadoras de las relaciones entre atractivo de la presentación}

Se pretendió analizar la medida en que el hábito de consumo o las variables sociodemográficas moderaban la relación entre el atractivo de las presentaciones y las variables intención de consumo, percepción de calidad y adecuación del diseño a la categoría.

Los resultados evidenciaron que las variables conocimiento de la marca, edad o estatus socioeconómico no afectaron a ninguna de las tres relaciones. Es decir, en su relación con el atractivo de la presentación, la intención de consumo, la percepción de calidad o la valoración del diseño como adecuado a la categoría no aumenta o disminuye por el efecto de estas variables.

Sin embargo, las variables frecuencia de consumo y género sí ejercen de variables moderadoras. Cuando el nivel de atractivo del empaque es bajo, los encuestados con una mayor frecuencia de consumo (respecto a los de menor frecuencia) perciben menor calidad en el producto, tienen menos intención de consumirlo y valoran su diseño como menos apropiado para un vino. $\mathrm{Y}$ al contrario, cuando el packaging es atractivo, perciben mayor calidad, manifiestan mayor probabilidad de consumirlo y valoran el diseño como más apropiado para la categoría vino. Los consumidores que declaran una frecuencia elevada de consumo son más críticos y penalizan las presentaciones de los vinos no atractivas, mientras que premian aquellas presentaciones de vinos más atractivas.

Lo mismo sucede en el caso del género. Cuando el diseño del producto no es atractivo las mujeres (en comparación con los hombres) perciben menor calidad en el producto, valoran su diseño como menos apropiado y manifiestan menor probabilidad de consumirlo. Justo lo contrario sucede cuando el diseño es atractivo. Las mujeres perciben mayor calidad en el producto que los hombres, manifiestan mayor probabilidad de consumirlo y valoran el diseño como más apropiado. En definitiva, las mujeres son más exigentes con aquellos vinos que no cuidan el atractivo de su imagen, mientras que se muestran más generosas cuando la presentación del producto es atractiva. Estos resultados suponen que si bien el atractivo de nuestro producto es importante, supone un elemento clave si nuestro producto va dirigido especialmente al público femenino. 


\section{e) Tipologías de diseño}

Los diseñadores valoraron la presentación de los vinos en base a 6 criterios de clasificación (véase apartado 8). El resultado permitió clasificar los vinos en 5 tipologías: “Transgresor en categoría”, en línea con muchos vinos internacionales; “Transgresor fuera de categoría”, que se sale de la categoría arriesgando mucho el mensaje emitido; "Tradicional con diseño cuidado", con la línea clásica del vino canario pero más pensada y evolucionada; "Tradicional con poco cuidado", que aunque parecen estar en la categoría no parecen cuidar el diseño y finalmente "Tradicional fuera de categoría”, que además de lo anterior están fuera de la categoría del producto. Véase el apartado 8.2 para una descripción más detallada de cada una de las tipologías.

Estas tipologías, claramente diferenciadas, muestran que el packaging de un vino, si desea ser atractivo, generar expectativas de calidad y aumentar las probabilidades de ser consumido, debe ser "Transgresor dentro de la categoría" o "Tradicional con diseño cuidado". Estas dos tipologías son las que mayor puntuación media obtienen en las tres variables y están en un nivel alto de valoración (por encima del 7 sobre 10).

El packaging que trabaja en su diseño el concepto "Tradicional" siempre tiene un cierto atractivo, pero su valoración es ligeramente más baja cuando no cuida el diseño y/o está fuera de la categoría.

Finalmente el vino que muestra un diseño "Transgresor fuera de categoría" tiene muchas probabilidades de tener muy bajo atractivo y percepción de calidad, así como baja intención de consumo. Por tanto es un gran riesgo decidir un diseño alineado con esta tipología. 

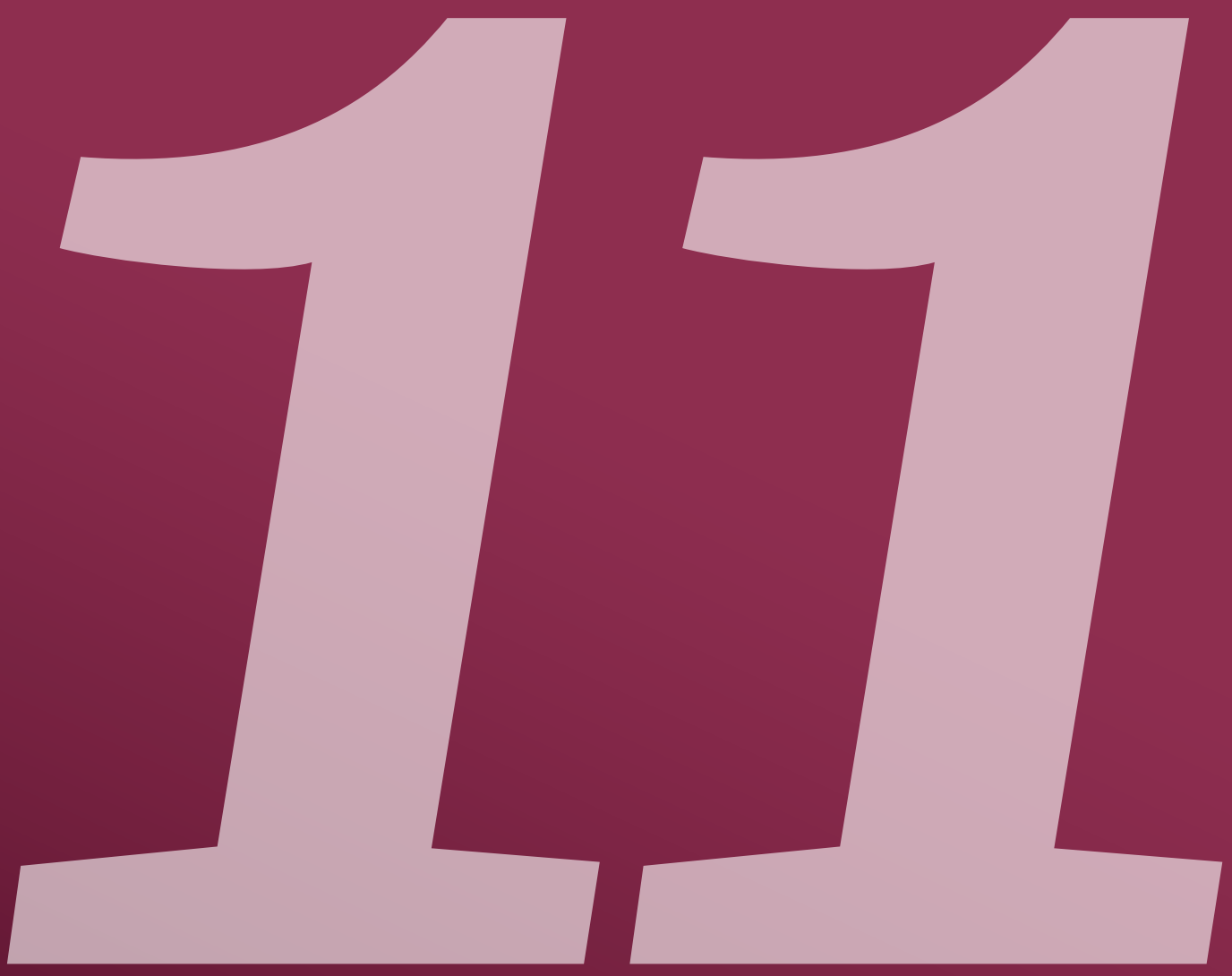

\section{Recomendaciones}




\section{Recomendaciones}

Por último, y sustentado en los principales resultados obtenidos del estudio, se realizan una serie de recomendaciones a los agentes del sector vitivinícola de Canarias en relación a los aspectos a tener en cuenta en el diseño de las presentaciones del vino.

1. Debe ponerse gran atención a los elementos extrínsecos, especialmente la presentación pues como se ha contrastado afecta directamente y de forma relevante a la intención de consumo y a la calidad percibida del producto.

Debemos tener en cuenta que un diseño poco atractivo puede estar lastrando el consumo del producto dado que los consumidores minusvaloran su calidad y, por tanto, la probabilidad de consumirlo es menor. Optimizar la presentación de un vino va a hacer que los consumidores perciban una calidad en el producto superior a la real, aumentando así las probabilidades de consumirlo.

2. Es necesaria una adecuación del diseño a las características del segmento al que se dirige y al concepto de valor propuesto. Existen grupos de consumidores con juicio crítico para evaluar con menor calidad y mostrar menor intención de consumo ante presentaciones poco atractivas, como son los consumidores con mayor experiencia o el género femenino que cada vez tiene un mayor peso en el mundo del consumo de vino. Por tanto, es necesario obrar con cautela y tomar decisiones objetivas en cuanto al diseño.

3. Se requiere profesionalizar el diseño. El diseño debe ser pensado y elaborado en colaboración con expertos en diseño. Lo contrario genera tipologías que no cuidan el diseño o peor aún, incoherentes con la categoría vino. Esto tiene unos efectos muy significativos y negativos en el valor del producto que afectan claramente a la calidad percibida y a su bajo consumo.

La presentación de los vinos debe adaptarse al segmento pero siguiendo una línea acorde con las tipologías de diseño "Transgresor dentro de la categoría" o "Tradicional con diseño cuidado" descritas en este trabajo. Estas nos muestran las directrices a seguir para realzar la calidad percibida de nuestro producto e incrementar la probabilidad de consumo. 
4. Es necesario testar los empaques previamente antes de salir al mercado. Como el diseño no es una ciencia exacta es conveniente testar la propuesta de diseño, antes de ser ofertada al mercado. De esta forma, podremos calibrar los riesgos y no perder oportunidades de mercado que, a raíz de lo expuesto anteriormente, seguramente ocurrirá si nuestro packaging no tiene el atractivo requerido o el contenido del mensaje emitido no se ajusta a la categoría, con un diseño alineado con las tendencias del mercado. En este sentido, deben evitarse sesgos personales, tanto del productor como del diseñador, bastante frecuentes en los diseños de este tipo de producto.

5. Deben fomentarse los encuentros sociales de consumo del vino entre diferentes generaciones, donde se den a conocer las marcas canarias y sean degustadas. Con ello se mejora e impulsa la percepción de atractivo y calidad del producto y la intención de consumirlo (siempre y cuando cuiden el atractivo del packaging). 


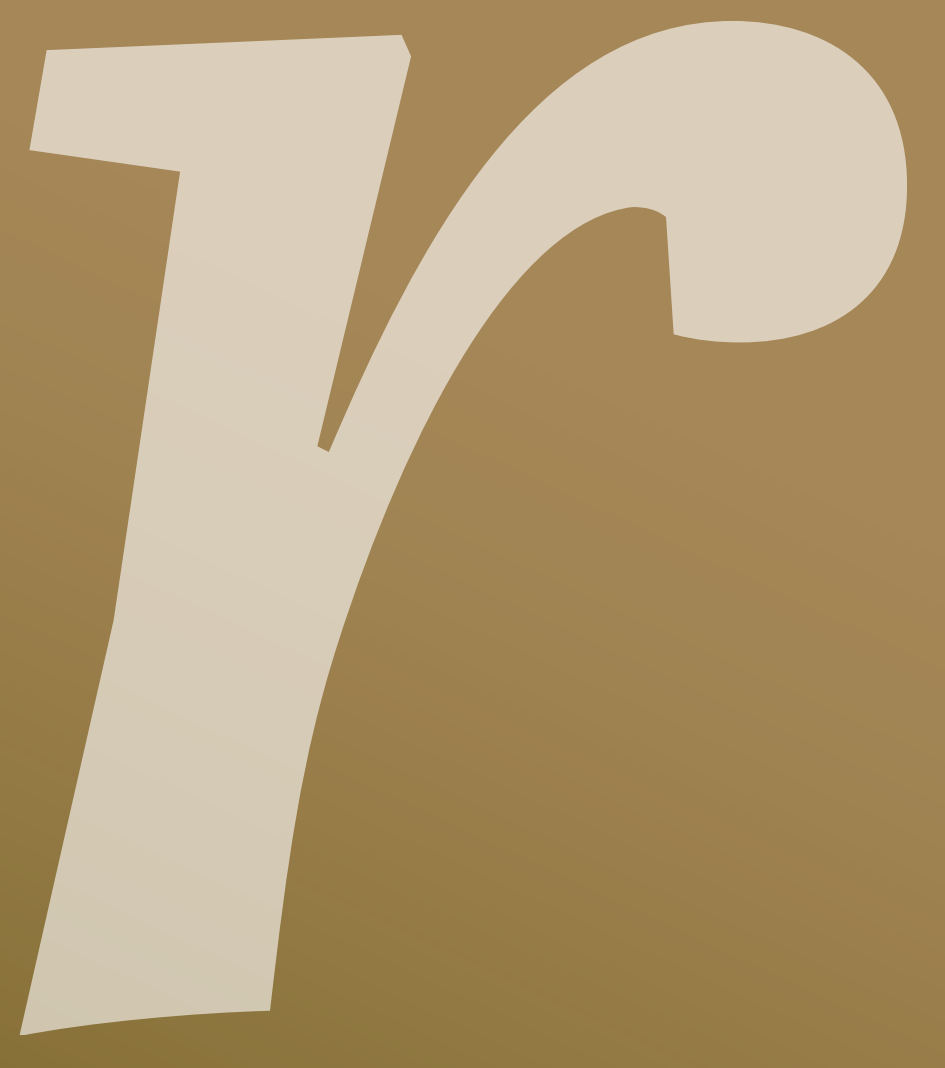

\section{Referencias}




\section{Referencias}

Abdelazim-Mohamed, N. B., García-Medina, I., y González-Romo, Z. F. (2019). E-commerce vs. tienda física. El packaging como elemento de influencia en la compra. RIIIT, $7(38)$.

Abdullah, F., \& Anagreh, B. (2011). The extent of awareness of managers of Jordanian industrial companies regarding the important of the commodity packaging quality from the viewpoint of the consumer. International Journal of Contemporary Research Business, 2, 142-148.

Adofo, A. (2014). The effect of beauty product packaging on consumer buying decision. The Business and Management review, 5(3), 14-21.

Atkin, T., Nowak, L. \& García, R. (2007).Womenwine consumers: information search and retailing implications. International Journal of Wine Business Research 19(4), 327-339.

Boudreaux, C. A., \& Palmer, S. E. (2007). A charming little Cabernet: effects of wine label design on purchase intent and brand personality. International Journal of Wine Business Research, 19, 170-186.

Charters, S., Lockshin, L., \& Unwin, T. (1999). Consumer responses to wine bottle back labels. Journal of Wine Research, 10, 183-195.

Di Vita, G., Caracciolo, F., Brun, F., \& D’Amico, M. (2019). Picking out a wine: Consumer motivation behind different quality wines choice. Wine economics and policy, 8(1), 16-27. https://doi.org/10.1016/j.wep.2019.02.002

Díaz-Armas, R, Gutiérrez-Taño, D, Hernández-Méndez, J., Ramos-Henriquez, J.M., Baute-Díaz, N. \& Sabina-del-Castillo, E. (2020). Hábitos de consumo de vino en Canarias. Frenos e impulsores al consumo de vinos canarios. Ed. Fundación General de la Universidad de La Laguna.

Elías-Pastor L.V. \& Contreras-Villaseñor, M. (2013). El paisaje del viñedo en las Islas Canarias. Colección Pasos no ${ }^{11}$. Edita PASOS. (último acceso el día 20 diciembre 2020 http://www.pasosonline.org/Publicados/pasosoedita/ PSEdita11.pdf)

Favier, M., Celhay, F., \& Pantin-Sohier, G. (2019). Is less more or a bore? Package design simplicity and brand perception: an application to Champagne. Journal of Retailing and Consumer Services, 46, 11-20. 
Gelici-Zeko, M. M., Lutters, D., Klooster, R., y Weijzen, P. L. G. (2013). Studying the influence of packaging design on consumer perceptions (of dairy products) using categorizing and perceptual mapping. Packaging Technology and Science, $26,215^{-228 .}$

Gmuer, A., Siegrist, M., \& Dohle, S. (2015). Does wine label processing fluency influence wine hedonics? Food Quality and Preference, 44, 12-16.

Gobierno de Canarias (2016). Informe Estadístico del Mapa de cultivos de Canarias. (último acceso el día 20 diciembre 2020 https://www. gobiernodecanarias.org/cmsgobcan/export/sites/agricultura/galerias/doc/ obrasRegadios/DOSSIER_Canarias_MCultivos_O1JUN2016.pdf)

Goode, J. (2005). Wine science. London: Mitchell Beazley.

Goode, J. (2016). I taste red: the science of tasting wine. London: Fine Wine Editions.

Grundey, D. (2010). Functionality of product packaging: Surveying consumers' attitude towards selected cosmetic brands. Economics and Sociology, 3(1), 87-103.

Heatherly, M., Dein, M., Munafo, J. P., \& Luckett, C. R. (2019). Crossmodal correspondence between color, shapes, and wine odors. Food Quality \& Preference, 71, 395-405.

ICCA (Instituto Canario de Calidad Agroalimentaria) (2010). Manual del consumidor de vinos de Canarias. (último acceso el día 20 diciembre 2020 https://www.gobiernodecanarias.org/agricultura/doc/icca/doc/publicaciones/ guiavino2010.pdf)

ISTAC (Instituto Canario de Estadística) (2020). Datos de la Consejería de Agricultura, Ganadería y Pesca (Datos consultados el 20 de diciembre de 2020 www.gobiernodecanarias.org/istac)

Karimi, P., Mahdieh, O., y Rahmani, M. (2013). The study of the relationship between packaging elements and purchase behavior. Interdisciplinary Journal of contemporary research in Business, 5(3), 281-295.

Lick, E., König, B., Kpossa, M. R., \& Buller, V. (2017). Sensory expectations generated by colours of red wine labels. Journal of Retailing and Consumer Services, 37(Supplement C), 146-158. 
Liu, H., Cella, D., Gershon, R., Shen, J., Morales, L. S., Riley, W., \& Hays, R.D. (2010). Representativeness of the PROMIS internet panel. Journal of Clinical Epidemiology, 63(11), 1169-1178. https://doi.org/10.1016/j.jclinepi.2009.11.021

Lockshin, L., \& Cohen, E. (2011). Using product and retail choice attributes for cross national segmentation. European Journal of Marketing. 45(7/8). 1236-1252. https://doi.org/10.1108/o3090561111137697

Lockshin, L., \& Corsi, A. M. (2012). Consumer behaviour for wine 2.0: A review since 2003 and future directions. Wine Economics and Policy, 1(1), 2-23. https://doi.org/10.1016/j.wep.2012.11.003

Lockshin, L., \& Corsi, A. M. (2020). Consumer Research For Wine. Handbook of Eating and Drinking: Interdisciplinary Perspectives, 525-542. https://doi. org/10.1007/978-3-030-14504-0_162

Lockshin, L., \& Hall, J. (2003). Consumer purchasing behaviour for wine: what we know and where we are going (Doctoral dissertation, University of South Australia, Wine Marketing Research Group). In http://academyofwinebusiness. com/wp-content/uploads/2010/o5/File-030.pdf

Lunardo, R., \& Livat, F. (2016). Congruency between color and shape of the front labels of wine: effects on fluency and aroma and quality perceptions. International Journal of Entrepreneurship and Small Business, 29(4), 528-541.

Mueller, S., \& Szolnoki, G. (2010). The relative influence of packaging, labelling, branding and sensory attributes on liking and purchase intent: Consumers differ in their responsiveness. Food quality and preference, 21(7), 774-783. https://doi.org/10.1016/j.foodqual.2010.07.011

Mueller, S., Lockshin, L., Saltman, Y., \& Blanford, J. (2010). Message on a bottle: the relative influence of wine back label information on wine choice. Food Quality and Preference, 21, 22-32.

Newman, K.A. (2009). Packaging is critical to brand identity. Global cosmetics industry magazine.

OEMV (Fundación Observatorio Español del Mercado del Vino) (2020). Compras de vino y otras bebidas en el canal de alimentación español (Datos consultados el 20 de diciembre de 2020 https://oemv.es/dr/2844) 
Orth, U. R., \& Crouch, R. C. (2014). Is beauty in the aisles of the retailer? Package processing in visually complex contexts. Journal of Retailing, 90(4), 524-537. https://doi.org/10.1016/j.jretai.2014.05.004

Orth, U. R., \& Malkewitz, K. (2008). Holistic package design and consumer brand impressions. Journal of marketing, 72(3), 64-81. https://doi.org/10.1509/ JMKG.72.3.064

Orth, U. R., Campana, D., \& Malkewitz, K. (2010). Formation of consumer price expectation based on package design: attractive and quality routes. Journal of Marketing Theory and Practice, 18(1), 23-40.

Roster, C. A., Rogers, R. D., Albaum, G., \& Klein, D. (2004). A comparison of response characteristics from web and telephone surveys. International Journal of Market Research, 46(3), 359-374.

Rozin, P. (2006). Domain denigration and process preference in academic psychology. Perspectives in Psychological Science, 1, 365-376.

Shaw, M., Keeghan, P., \& Hall, J. (1999). Consumers judge wine by its label, study shows. Australian and New Zealand Wine Industry Journal, 14(1), 84-87.

Silayoi, P., \& Speece, M. (2004). Packaging and purchase decisions: an exploratory study on the impact of involvement level and time pressure. British Food Journal, 106, 607-628.

Silayoi, P., \& Speece, M. (2007). The importance of packaging attributes: a conjoint analysis approach. European Journal of Marketing, 41, 1.495-1.517.

Spence, C. (2020). Wine psychology: basic \& applied. Cognitive Research: Principles and Implications, 5(22), 1-18.

Stoll, M., Baecke, S., y Kenning, P. (2008). What they see is what they get? An fMRI-study on neural correlates of attractive packaging. Journal of Consumer Behaviour, 7, 342-359.

Thomas, A., \& Pickering, G. (2003). The importance of wine label information. International Journal of Wine Marketing, 15(2), 57-73.

Thomas, W. A., (2000). Elements influencing wine purchasing: a New Zealand view. International Journal of Wine Marketing. 12(2). 47-61.

https://doi.org/10.1108/eboo8709

Influencia del atractivo de la presentación de los vinos en la percepción 
Underwood, R. L., Klein, N. M., \& Burke, R. R. (2001). Packaging communication: attentional effects of product imagery. Journal of product $\&$ brand management. 10 (7), 403-422. https://doi.org/10.1108/10610420110410531

Venter, K., van der Merwe, D., de Beer, H., Kempen, E., \& Bosman, M. (2011). Consumers' perceptions of food packaging: an exploratory investigation in Potchetstroom, South Africa. International Journal of Consumer Studies, 35, 273-281.

Zeithaml, V.A. (1988). Consumer Perceptions of Price, Quality, and Value: A Means-End Model and Synthesis of Evidence. In Journal of Marketing, 52, 2-22.

Zoecklein, B., Fugelsang, K., Gump, B., \& Nury, F. (1995). Wine analysis and production. New York: Chapman and Hall. 
